\title{
Arquitectura y cerámica de Casas Grandes. Una comparación entre conceptos espaciales arquitectónicos y pictóricos
}

\section{Casas Grandes Architecture and Pottery: A Comparison between Architectural and Pictorial Spatial Concepts}

Artículo recibido el 6 de diciembre de 20I5; devuelto para revisión el II de febrero de 20I6; aceptado el Io de marzo de 20I6. http://dx.doi.org/Io.2220I/iie.I8703062e.20I6.IO9.2580

Georgina Parada Carrillo Maestra en Historiadel Arte por partedela unam.giny_p@hotmail.com

Líneas de investigación Arte indígena precolombino orientado al análisis del espacio en la escultura en piedra, pintura cerámica y arquitectura.

Resumen El artículo tiene como objetivo hacer un análisis comparativo entre determinados conceptos espaciales de la arquitectura de la ciudad precolombina de Casas Grandes y los diseños pictóricos de su cerámica polícroma. Dicha comparación revelará profundas similitudes que apuntan hacia una posible relación con los ya perdidos rituales de la cultura Casas Grandes. Sin intención de perseguir una interpretación, o de atender problemas de índole histórica o arqueológica, el texto se enfoca en cuestiones exclusivamente plásticas, en las que el modo de representar la llamada greca escalonada tendrá un papel predominante.

Palabras clave arquitectura precolombina; cerámica; espiral; greca escalonada; geometría; Paquimé; Casas Grandes; diseńos pictóricos, ritual.

Abstract The essay focuses on certain spatial concepts that emerge from the comparative analysis of the architecture of the pre-Columbian city of Casas Grandes and the pictorial designs on its polychrome pottery. This comparison reveals profound similarities that point to plausible correspondences with long lost Casas Grandes rituals. Without seeking to present an unequivocal interpretation or address problems of an archaeological or historical nature, the text concentrates on plastic issues; among these, a preeminent role is played by the way the stepped fret is executed.

Keywords Pre-Columbian architecture; pottery; spiral; step fret; geometry; Paquimé, Casas Grandes; pictorial designs; ritual. 
DOI: http://dx.doi.org/10.22201/iie.18703062e.2016.109.2580 
DOI: http://dx.doi.org/10.22201/iie.18703062e.2016.109.2580

\author{
GEORGINA PARADA CARRILLO
}

\title{
Arquitectura y cerámica de Casas Grandes \\ Una comparación entre conceptos espaciales arquitectónicos y pictóricos
}

\section{L} a ciudad precolombina de Casas Grandes (Paquimé) está inmediatamente ligada a la persona de Charles C. Di Peso, el arqueólogo estadounidense encargado de su excavación entre 1958 y 1961. A pesar de las interminables discusiones a favor y en contra de sus polémicas hipótesis, tuvo la suficiente sensibilidad para sacar a la luz aspectos arquitectónicos que atañen a la historia del arte, y que hoy día, a más de medio siglo de sus conjeturas, son poco o nulamente estudiados. Me refiero al esquema urbano "revertido", donde las estructuras ceremoniales no se encuentran al centro, sino dispersas en torno a la vivienda, las complejas habitaciones de muros escalonados vistos en planta, y los montículos con diseños curvos y zoomorfos, ${ }^{\mathrm{I}}$ cuya identificación, como propone el autor, es dudosa, pero están configurados mediante recorridos en espiral. Estos rasgos son expresamente distintivos de Casas Grandes e inclusive muestran cierta excepcionalidad.

Lo que me interesa demostrar en este ensayo es que todos estos aspectos tienen su paralelo en los diseños pictóricos de la cerámica polícroma de Casas Grandes, cuya mayor producción coincide con el lapso del florecimiento de

I. Charles C. Di Peso, Casas Grandes: A Fallen Trading Center of the Gran Chichimeca, vol. 2 (Dragoon: The Amerind Foundation, 1974), 394 y 429; y Charles C. Di Peso, John B. Rinaldo y Gloria J. Fenner, Casas Grandes: A Fallen Trading Center of the Gran Chichimeca, vols. 4 y 5 (Dragoon: The Amerind Foundation, 1974), 20I y 647. 
DOI: http://dx.doi.org/10.22201/iie.18703062e.2016.109.2580

174

GEORGINA PARADA CARRILLO

su arquitectura, ${ }^{2}$ entre 1300 y I450 d.C., dentro del llamado periodo Medio. Desde el punto de vista de la alfarería, sus diseños también guardan cierta excepcionalidad y peculiaridad como la estricta falta de centro en la composición pictórica, la repetición casi obsesiva de dos elementos escalonados girados uno frente a otro y a menudo designados en negro y rojo, y la extrańa configuración de elementos zoomorfos con un grado de estilización que varía de un extremo naturalista a uno geométrico y en cuya composición casi siempre está implicada la espiral.

Estas comparaciones están condensadas en la figura I. Lejos de demostrar las semejanzas superficiales indicadas en la imagen, pues no ignoro las distintas problemáticas y soluciones de cada soporte artístico, el texto revelará similitudes más profundas que apuntan hacia un origen común, posiblemente relacionado con los ya perdidos rituales de la cultura de Casas Grandes. Sin intención de perseguir una interpretación inequívoca, mi objeto es proponer un punto de vista para aproximarnos a un arte tan poco entendido dada su predominancia geométrica y el sorprendente modo de representar un concepto tan enigmático como la simbiosis entre la espiral y la escalera.

\section{La arquitectura}

La expresividad de la arquitectura de Casas Grandes no ha sido ignorada por los estudiosos contemporáneos, quienes la han analizado desde nuevos enfoques como el animismo y la fenomenología. El primero ha buscado superar la limitada interpretación funcional tanto de su arquitectura como de otros objetos; ${ }^{3}$ el segundo ha demostrado que los contrastes entre las dos porciones de la ciudad no pueden expresarse a partir de la dualidad, pues cada una define a la otra mediante una interacción permanente. ${ }^{4}$

Esta dicotomía se refiere a dos patrones bien definidos: uno al oriente donde se concentran las unidades habitacionales, de rígidos muros ortogonales y

2. Michael E. Whalen y Paul E. Minnis, The Neighbors of Casas Grandes: Excavating Medio Period Communities of Northwest Chihuahua, Mexico (Tucson: The University of Arizona Press, 2009), iI8.

3. Christine S. VanPool y Todd L. VanPool, "Breath and Being: Contextualizing Object Persons at Paquimé, Chihuahua, Mexico", en Kathryn Roundtree, Christine Morris y Alan A.D. Peatfield, eds., Archaeology of Spiritualities (Nueva York: Springer, 2012), 87-106.

4. Delain Hughes, "Complementary Dualities: The Significance of East/West Architectural Difference in Paquimé”, tesis de Maestría en Artes (University of North Texas, 2005), 63. 


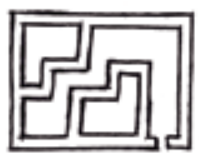

a. Viviendas de la Unidad 8.

Detalle de la vasija CG-698.
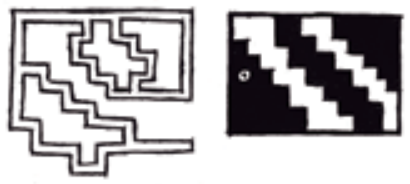

c. Viviendas de la Unidad I4.

Detalle de la vasija CG-6062.
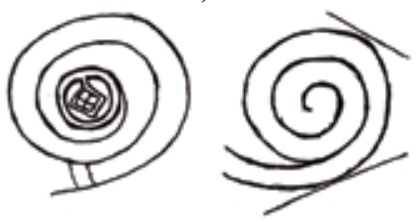

e. Torre sobre cerro Moctezuma.

Detalle de la vasija CG-4307.
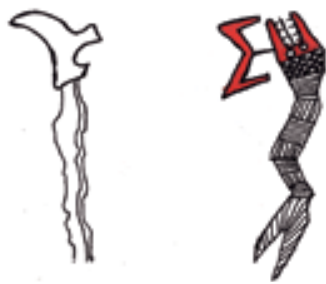

g. Montículo de la Serpiente.

Detalle de la vasija CG-3642.
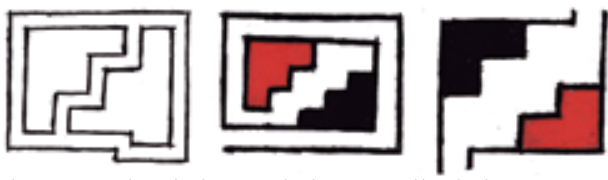

b. Viviendas de la Unidad 8. Detalle de las vasijas CG-269 y CG-4304.
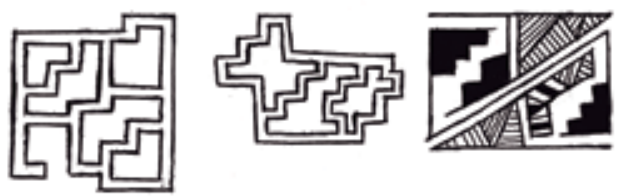

d. Viviendas de la Unidad I4. Detalle de la vasija CG-8566.
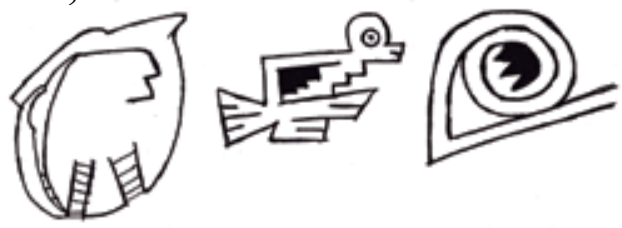

f. Montículo del Pájaro. Detalle de la vasija CG-6062.
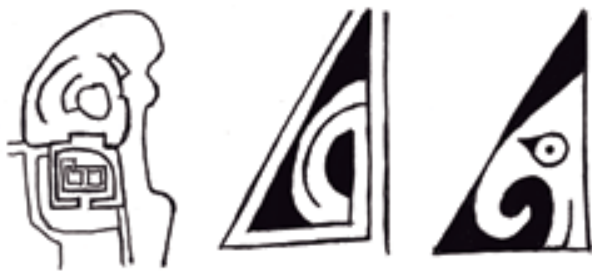

h. Montículo de las Ofrendas. Detalle de las vasijas CG-4368 y CG-O83O.

I. Comparación entre estructuras arquitectónicas y diseños pictóricos en la cerámica de Casas Grandes. Dibujo: Georgina Parada. 


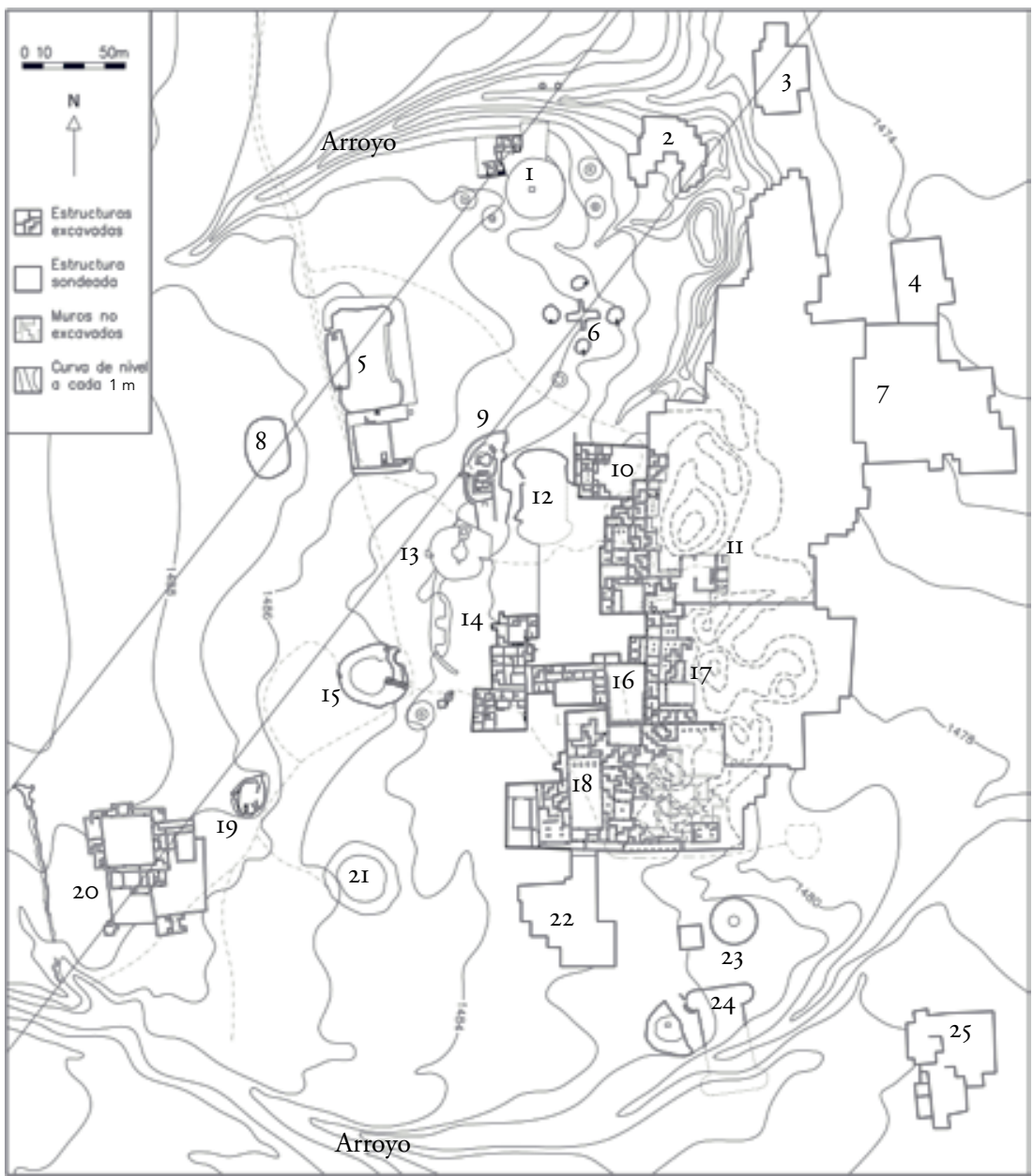

I. Unidad I, Casa de los Hornos

2. Unidad 23

3. Unidad $2 \mathrm{I}$

4. Unidad 22

5. Cancha I

6. Unidad 2, Montículo de la Cruz

7. Unidad I9

8. Unidad 5

9. Unidad 4, Montículo de las Ofrendas
Io. Unidad 6

II. Unidad 8, Casa de la Noria

I2. Cancha III

I3. Aljibe I

I4. Unidad I2, Casa de las Guacamayas

I5. Unidad 9, Montículo de los Héroes

I6. Unidad I3, Casa de los Muertos

I7. Unidad I6, Casa de los Cráneos
I9. Unidad ıo, Montículo del Pájaro 20. Unidad II, Casa de la Serpiente 2I. Aljibe 2

22. Unidad I5

23. Unidad I6

24. Cancha II

25 . Unidad 20

2. Casas Grandes, plano de la ciudad con dos líneas paralelas a 38. Dibujo: Georgina Parada, a partir del levantamiento y la digitalización de estructuras arquitectónicas realizadas por el Instituto Nacional de Antropología e Historia y del plano publicado en Di Peso, Rinaldo y Fenner, Casas Grandes (vid. supra n. I), vol. 5, fig. 285. 


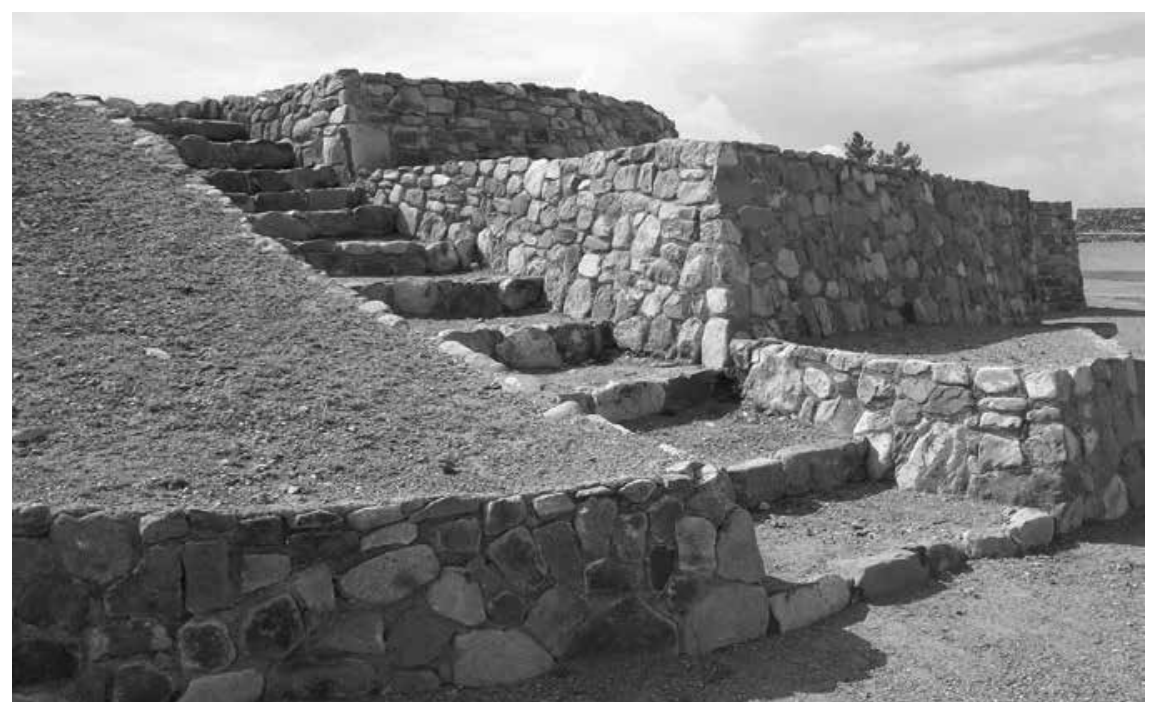

3. Casas Grandes, Montículo de los Héroes (Unidad 9). Foto: Georgina Parada. Secretaría de Cultura-INAH-Méx. "Reproducción autorizada por el Instituto Nacional de Antropología e Historia”.

escalonados; otro al poniente y sur donde se diseminan algunas viviendas aisladas y las estructuras consideradas como públicas o ceremoniales con la predominancia de formas curvas, más libres (fig. 2).5 La segmentación espacial entre estas mitades responde más bien a un eje diagonal, derivado del contorno escalonado del complejo y de las estructuras individuales alineadas en sentido noreste-suroeste, con una inclinación cercana a $38^{\circ}$.

Es probable que las entradas a la ciudad se encontraran al sur y principalmente al este del conjunto habitacional, ${ }^{6}$ que coincide con el arribo desde el río y se evidencia por las columnatas en la Unidad I4. Desde esta perspectiva las estructuras público-ceremoniales, siete montículos y dos canchas de juego de pelota, se desenvuelven tímidamente detrás de la gran masa de viviendas

5. Para mi análisis considero sólo las 23 unidades que Di Peso excavó y sondeó, tal como aparecen en la figura 2, por tanto, rechazo la controvertida existencia de una plaza central y de un conjunto situado al oriente, propuestos por él, y que todavía son materia de discusión entre investigadores, postura que he tomado al seguir la incomparable experiencia del arqueólogo Eduardo Gamboa en el sitio de Casas Grandes.

6. Eduardo Gamboa, comunicación personal, 2013. 
DOI: http://dx.doi.org/10.22201/iie.18703062e.2016.109.2580

178

GEORGINA PARADA CARRILLO

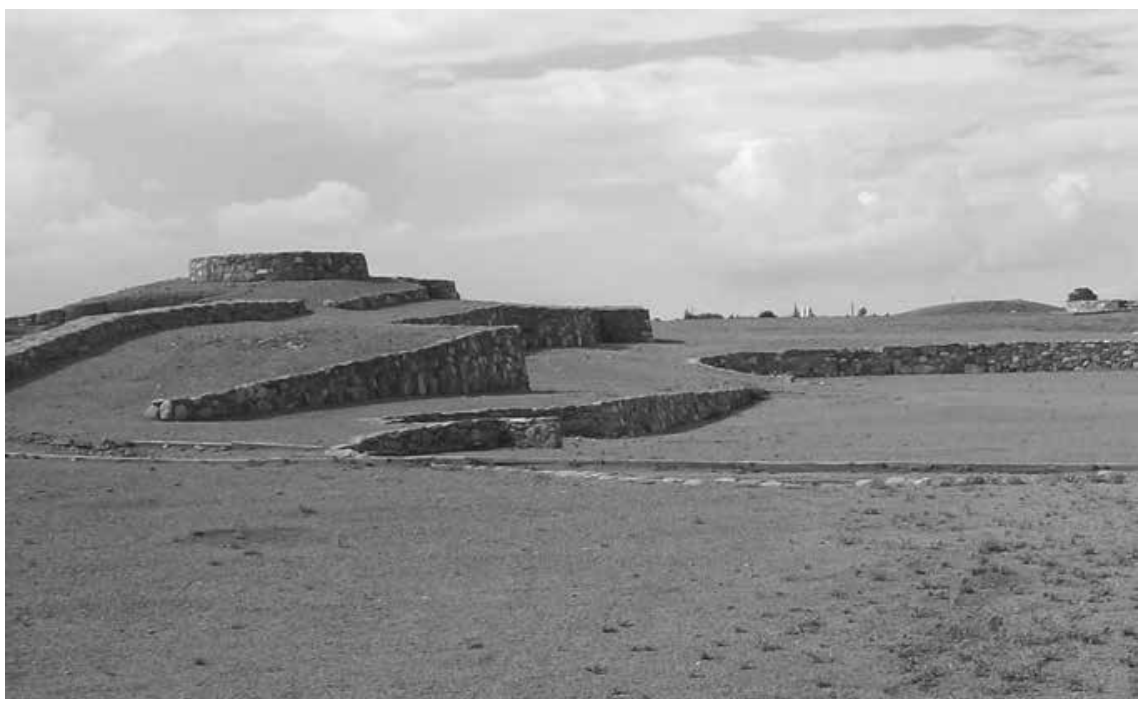

4. Casas Grandes, Montículo de las Ofrendas (Unidad 4). A la derecha se observa una cancha de juego de pelota. Foto: Georgina Parada. Secretaría de Cultura-INAH-Méx. "Reproducción autorizada por el Instituto Nacional de Antropología e Historia”.

(quizá sobrepasaba los tres niveles de altura), 7 sin intención de destacar en el paisaje (figs. 3-5). Cinco de los montículos mantienen una alineación suroeste-noreste, la cual corre desde el extremo sur del Montículo de la Serpiente (al poniente de la Unidad II) hasta el Montículo de la Cruz (Unidad 2), e incluso puede extenderse a dos unidades más (las unidades habitacionales 23 y 2I), que se hallan aproximadamente sobre la misma altitud. Los cinco se suceden de manera rítmica con un espaciamiento más o menos constante. Ninguno domina sobre otro, por lo que puede sugerirse que todos gozaban de la misma

7. Baltasar de Obregón en el siglo Xvi refiere seis o siete niveles (citado por Di Peso, Rinaldo y Fenner, Casas Grandes, vol. 4, II3). John R. Bartlett, durante su visita en I850, calcula hasta 50 pies o seis pisos de altura (John R. Bartlett, A Personal Narrative of Explorations and Incidents in Texas, New Mexico, California, Sonora and Chihuahua. Connected with the United States and Mexican Boundary Comission during the Years 1850-1853, vol. II [Chicago: The Rio Grande Press, I965], 350). Adolph Bandelier, quien visitó las ruinas a finales del siglo xix, considera la posibilidad de cuatro niveles (Bandelier, The Southwestern Journals of Adolph F. Bandelier, I883-1884, eds. Charles Lange y Carroll L. Riley [Alburquerque: The New Mexico University Press, 1970], 295). 


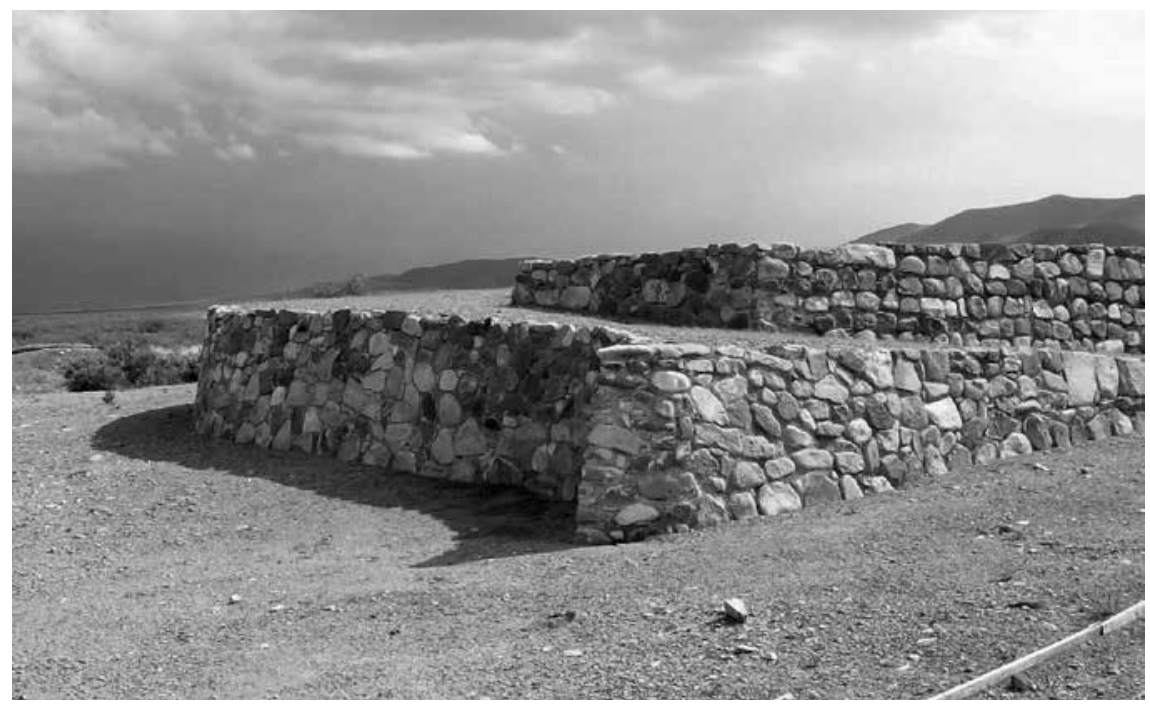

5. Casas Grandes, Montículo del Pájaro (Unidad 19). Foto: Georgina Parada. Secretaría de Cultura-INAH-Méx. "Reproducción autorizada por el Instituto Nacional de Antropología e Historia”.

posición jerárquica. Dichas estructuras se han relacionado con el sistema de clanes, en el que cada una representaría un grupo social encargado de tareas específicas. $^{8}$

Esta disposición urbana merece especial atención, pues las estructuras ceremoniales se alinean con la torre cilíndrica de rampa helicoidal sobre la cima del cerro Moctezuma, un cerro de trincheras ubicado a seis kilómetros al suroeste de la ciudad (fig. 6).9 Si ignoramos la distancia que separa este elemento de la ciudad, concepto por demás relativo, dicha torre se inserta como una "estación" más en la cadena de montículos ceremoniales. Su forma no es propiamente una singularidad, pues las espirales son un elemento recurrente en los cerros de

8. El clan de la serpiente podría ser un ejemplo de ello, el cual tendría a su cargo los trabajos de irrigación (Gamboa, 2013).

9. Las relaciones visuales entre uno y otro montículo se desarrollaron extensamente en un trabajo al que ya hice mención; por supuesto el autor no ignora las distintas alineaciones posibles entre estructuras arquitectónicas, aunque no hace mención a la línea con el cerro (Hughes, "Complementary Dualities", 76-78). 
DOI: http://dx.doi.org/10.22201/iie.18703062e.2016.109.2580

I80

GEORGINA PARADA CARRILLO

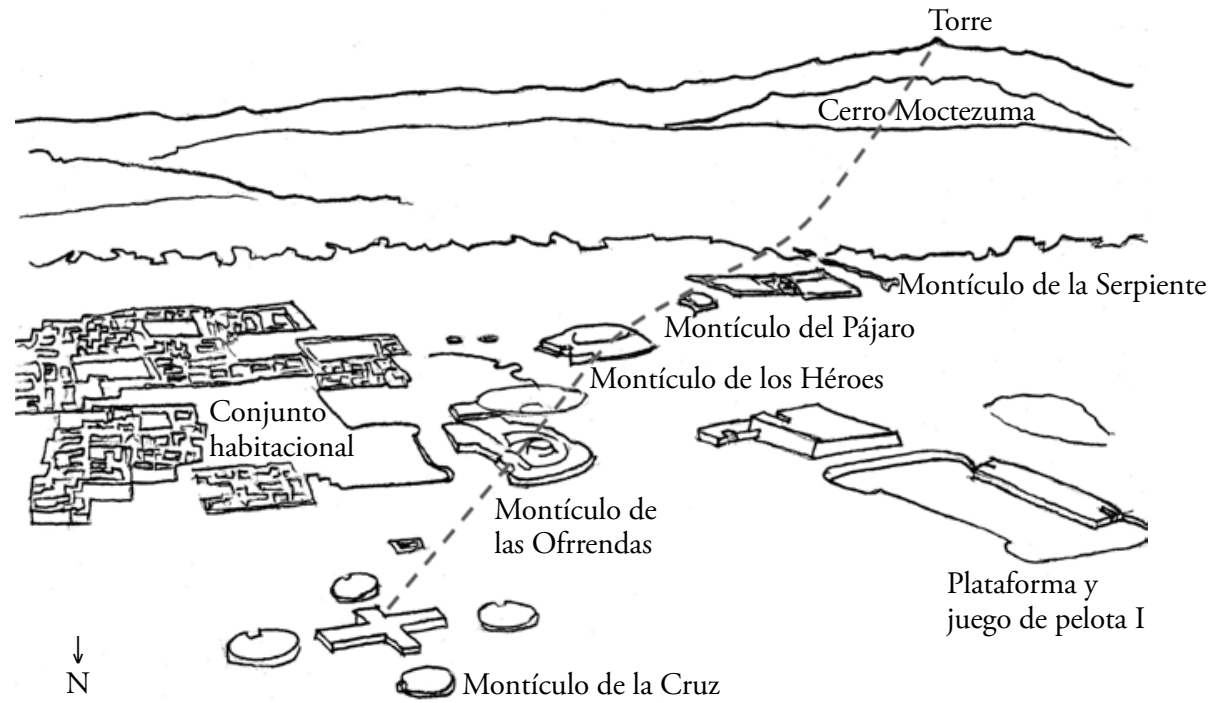

6. Casas Grandes, relación entre las estructuras ceremoniales y la torre sobre el cerro Moctezuma. Dibujo: Georgina Parada, basado en una fotografía publicada por el Centro INAH Chihuahua (www.inahchihuahua.gob.mx). Secretaría de Cultura-INAH-Méx. "Reproducción autorizada por el Instituto Nacional de Antropología e Historia”.

trincheras, así como las pequeñas torres o corrales construidos en las cimas. ${ }^{10}$ Di Peso identificó el cerro y su torre con un supuesto culto a Ehécatl, ${ }^{\mathrm{II}}$ aunque la discusión de dicha hipótesis está fuera de la temática de este ensayo, la relación entre la espiral y el viento es incuestionable. Efectivamente embisten a la ciudad fuertes vientos provenientes del suroeste, más en concreto desde el cerro, y se confirma de este modo la importancia capital que este elemento paisajístico juega en el urbanismo.

Otro aspecto sustenta que esta alineación sea un elemento primordial en la arquitectura; me refiero a la observación astronómica publicada por Di Peso sobre la ocultación de Sirio, la estrella más brillante del firmamento, fenóme-

Io. Bridget Zavala, "Elevated Spaces: Exploring the Symbolic at Cerros de Trincheras", en Christine S. VanPool, Todd L. VanPool y David A. Phillips, eds., Religion in the Prehispanic Southwest (Lanham: AltaMira Press, 2006), I42. La estructura más famosa de este tipo es sin duda "El Caracol" en Cerro de Trincheras, Sonora.

II. Di Peso, Casas Grandes, vol. 2, 365 y 549. 
no que sucede detrás de la referida torre, vista desde el Montículo de la Cruz. ${ }^{\text {I2 }}$ Esta observación no debería ignorarse, pues la cruz tenía un carácter estelar entre los pueblos precolombinos del noroeste. ${ }^{\mathrm{I3}}$ Aunque se ha identificado este montículo como una representación de Venus, ${ }^{14}$ un vistazo al complejo religioso de los indios pueblo denota un panorama astral considerablemente más rico. Hago esta comparación porque es muy probable que en Casas Grandes existiese una fuerte tradición pueblo. ${ }^{15}$ En esta cultura las estrellas actúan como guías del hombre, y Sirio parece cumplir un papel de mediador entre el ser humano y el mundo animal: "Ésta es la estrella que controla la vida de todos los seres en el reino animal. Su aparición completa el patrón armónico del Creador, quien ordenó que el hombre debe vivir en armonía con todos los animales de este mundo". ${ }^{16}$

Respecto a las estructuras zoomorfas es difícil deducir una identificación precisa con imágenes de aves o guacamayas como Di Peso propone, con excepción de la serpiente (fig. 2, esquina suroeste). Si llegaron a representar un objeto concreto, la restauración no permite apreciarlo. Considero más valioso su papel dentro de la actividad y el ritual, pues su escasa altura y los recorridos que dibujan proponen conceptos de movimiento y dirección en el contexto religioso de Casas Grandes, además de aludir a imágenes de contenido simbólico. El Montículo de la Serpiente ilustra esta suposición. Son por demás conocidas las evocaciones acuáticas otorgadas a la representación de este animal, tema demasiado extenso para ser tratado aquí: ${ }^{17}$ lo significativo para este trabajo es que la posición de su cabeza indica un desplazamiento hacia el norte, al igual que el río Casas Grandes, de modo que es el movimiento y

I2. Di Peso, Rinaldo y Fenner, Casas Grandes, vol. 4, 288.

13. Carroll L. Riley, The Kachina and the Cross: Indians and Spaniards in the Early Southwest (Salt Lake City: The University of Utah Press, 1999), 156.

I4. Marc Thompson, "Pre-columbian Venus: Celestial Twin and Icon of Duality", en Religion in the Prehispanic Southwest, 165-183.

I5. Stephen Lekson, "Was Casas a Pueblo?", en Curtis F. Schaafsma y Carroll L. Riley, eds., The Casas Grandes World (Salt Lake City: The University of Utah Press, 1999), 84-92.

I6. Frank Waters, Book of the Hopi (Nueva York: Ballantine Books, 1963), I84 (la traducción es mía). En otra ocasión los animales dicen a los hombres del clan de la Niebla en uno de los mitos hopi: "Tu estrella protectora será Ponóchona [Sirio], la estrella a quien debes pedir para incrementar el reino animal", Waters, Book of the Hopi, 299.

17. La conexión entre el control del agua y el citado montículo (relacionado iconográficamente con la serpiente de agua cornuda de otras partes del noroeste) ha sido desarrollada de manera amplia por los VanPool. Véase sobre todo VanPool y VanPool, "Breath and Being", 87-ro6. 

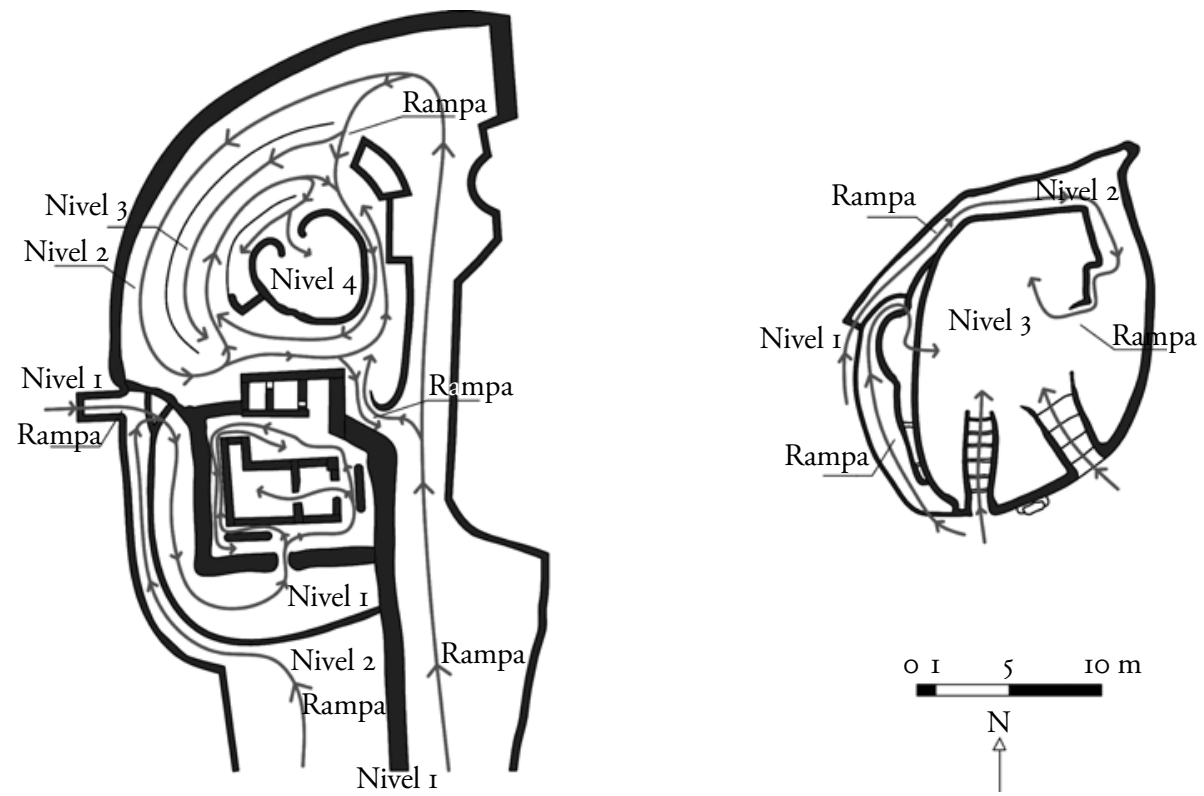

7. Casas Grandes, recorridos en el Montículo de las Ofrendas (Unidad 4) y en el Montículo del Pájaro (Unidad 19). Dibujos: Georgina Parada, a partir del levantamiento y la digitalización de estructuras arquitectónicas realizados por el Instituto Nacional de Antropología e Historia y los planos publicados en Di Peso, Rinaldo y Fenner, Casas Grandes (vid. supra n. I), vol. 4, 307 y 472 , figs. 218 y 324 .

la direccionalidad lo que aquél sustrae del agua, más allá de su forma u otra característica. Más adelante, al analizar las imágenes figurativas en la cerámica, esta conjetura se definirá con mayor claridad.

Además de la torre del cerro, otras dos estructuras presentan recorridos en espiral, los cuales describen un movimiento ascendente hacia el interior (fig. 7 ). En el Montículo de las Ofrendas los posibles caminos a lo largo de las rampas combinan el desplazamiento de la espiral y el meandro (o curvas paralelas). En el Montículo del Pájaro una espiral termina en forma escalonada. Todas ellas son configuraciones que encontramos en la cerámica (figs. re, $\mathrm{fy}$ h).

De nuevo un acercamiento a los indios pueblo induce a plantear seriamente la primacía de conceptos de movimiento, dirección y sentido en el mundo ritual de Casas Grandes. Durante la festividad Wúwuchim (primera ceremonia de invierno donde se pide por la germinación de todas las formas de vida 
en la tierra), cuatro grupos hopi realizan sucesivamente cuatro circuitos alrededor de la villa, cada uno más chico que el otro; distinguiendo entre un movimiento dextrógiro, cuando se vincula con el sol, y uno contrario, cuando se relaciona con la tierra. Al final se colocan frente a la kiva (casa comunal semisubterránea) desplazándose lentamente de derecha a izquierda en forma de arco, dejando un patrón armónico (¡escalonado?) en la arena. ${ }^{18}$

El concepto de movimiento que propone la sucesión y ausencias de jerarquías entre las estructuras ceremoniales se confirma por la inexistencia de un elemento troncal que supondría cierto estatismo en el urbanismo. La misma plaza referida como central en el proyecto de excavación, ubicada al sur del Juego de Pelota III (fig. 2), dista mucho de ser un centro, pues no existe ninguna característica que le confiera tal atributo, la mayoría de los muros de la vivienda que le rodean son ciegos y parte de la plaza en realidad pertenece a una cancha en forma de I cuya restauración está incompleta. ${ }^{19} \mathrm{La}$ falta de relaciones axiales en Casas Grandes ha generado que los principales estudios sobre el tema no contemplen una organización entre las estructuras ceremoniales. ${ }^{20}$ Más bien habría que pensarla bajo su propia lógica del espacio, independiente de cualquier distribución axial o centralizada. Lógica que se hará más patente al analizar el espacio interior de la vivienda.

Los arqueólogos coinciden en el supuesto de que la ciudad fue presa en determinado momento de una remodelación planeada, relacionada con un cambio político significativo. Durante estas transformaciones las unidades habitacionales, antes aisladas, crecieron hasta apiñarse en un solo conjunto masivo de varios niveles, que produjo manifiestos cambios en el espacio interior. Un esquema cercano a lo que llamaríamos central o arborescente, con habitaciones en torno a una plaza, a menudo rectangular y con columnas o pórticos, parece haber sido trastocado por elementos constructivos predominantemente escalonados. Se sabe que esta multitud de esquinas fueron benéfi-

18. Waters, Book of the Hopi, I8I.

19. Agradezco la observación de Gamboa, quien me indicó que efectivamente ésta es una cancha de juego de pelota (comunicación personal, 20I3); Di Peso no la contempla a pesar de tener las mismas dimensiones y un montículo adyacente al igual que los otros dos juegos.

20. A propósito de las unidades ceremoniales Beatriz Braniff dice: "En el plano de la ciudad vemos que estas unidades se encuentran frente al ala oeste, y la rodean por el norte y por el sur. Ninguna de ellas se ubica en forma organizada o simétrica con respecto a las demás, pues cada una ocupa un lugar y posición diferentes", Beatriz Braniff, Paquimé (México: Fondo de Cultura Económica, 2008), 67. 
DOI: http://dx.doi.org/10.22201/iie.18703062e.2016.109.2580

I84

GEORGINA PARADA CARRILLO

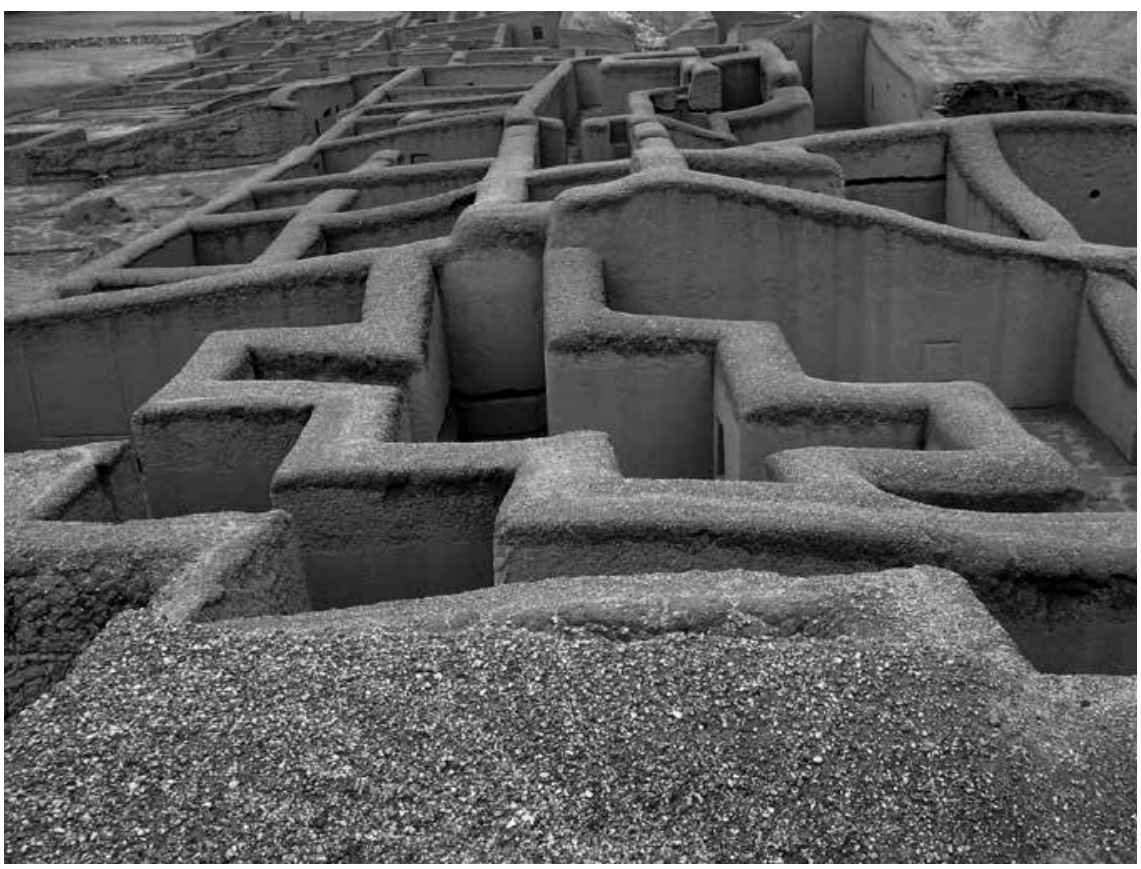

8. Casas Grandes, Casa de los Pilares (Unidad I4). Foto: Georgina Parada. Secretaría de Cultura-INAH-Méx. "Reproducción autorizada por el Instituto Nacional de Antropología e Historia”.

cas para sobrellevar el paso del tiempo, ${ }^{21}$ por lo cual es posible observar cómo estas construcciones sincretizan una necesidad trascendental con la gran cantidad de ángulos que requiere la construcción con tierra (fig. 8).

Proponer un punto de partida para analizar el espacio interior no es tarea fácil, debido a su confusa distribución laberíntica y al hecho de que más de la mitad del conjunto aún yace bajo tierra. $\mathrm{Al}$ examinar la planta arquitectónica desde la geometría analítica, es decir, con relación a su ubicación en un sistema de coordenadas cartesianas, pronto se descubre que su organización no concuerda con la percepción real. No es casualidad que David R. Wilcox haya adoptado un método procedente de las matemáticas modernas y la topología,

2I. Según Bartlett todas las esquinas y paredes cortas que formaban ángulos se mantenían en pie, al menos, durante su visita a mediados del siglo xix (Bartlett, A Personal Narrative, 353). 
como la teoría de grafos, para analizar el espacio interior en Casas Grandes. ${ }^{22} \mathrm{Su}$ propuesta demuestra que la importancia y el uso de los espacios se fundamentan en la relación entre ellos, y no por conceptos de forma, ubicación o tamaño. Cada habitación se define por factores como su accesibilidad respecto al exterior, si controla la permeabilidad de otra, o si existe una o más rutas alternas para llegar a ella. Sin intención de aplicar estrictamente su método, éste me proporcionó un comienzo para analizar el intrincado espacio habitacional (tres de estas unidades están reproducidas en la fig. 9). ${ }^{23}$ De modo que nos encontramos con grupos de habitaciones conectadas entre sí a los que Di Peso llamó clusters, sin vínculo directo con otros grupos adyacentes. A primera vista este agrupamiento se presenta arbitrario, no responde a una estructura discernible en planta. En los niveles superiores los grupos o clusters pueden no coincidir, por lo cual una habitación puede asirse a distinto grupo en cada nivel, concibiendo la totalidad del conjunto como una compleja red tridimensional, donde el intrincado y escalonado diseño en planta se repite en sección vertical.

El esquema escalonado produce pares de habitaciones divididas por un muro de dos, tres o hasta cuatro ángulos, los cuales recrean uno de los diseños más abundantes en la cerámica: las dos figuras escalonadas inscritas en un rectángulo (figs. Ia-d). Es significativo que a pesar de su proximidad estas parejas pueden estar remota o nulamente vinculadas, pues no hay forma de corroborar si era posible pasar de una a otra sin salir por completo del conjunto habitacional, a menos que existiese un camino, hoy desaparecido, a través de los niveles superiores (por ejemplo las habitaciones 7 y 8 de las Casas de la Noria y de los Pilares, fig. 9).

El tránsito entre un grupo y otro sólo es posible mediante patios o plazas interiores que, a su vez, se conectan entre ellos por habitaciones que debieron

22. Su método presenta una combinación entre una teoría sobre la lógica social del espacio desarrollada por Hillier y Hanson en 1984, que busca responder cómo nuestras acciones configuran el espacio para acomodarse a nuestras necesidades; y la teoría de grafos, un modo abstracto de expresar las relaciones entre los objetos, representado gráficamente por medio de nodos unidos con líneas (David R. Wilcox, "A Preliminary Graph-theoretic Analysis of Access Relationships at Casas Grandes", en The Casas Grandes World, 93-I04).

23. Para este análisis tomo en conjunto tan sólo las dos primeras fases constructivas del periodo Medio propuestas por Di Peso, pues posteriores pruebas de datación demuestran la dudosa separación entre ellas, y la falta de datos para determinar la temporalidad de la tercera (Jeffrey $S$. Dean y John C. Ravesloot, "The Chronology of Cultural Interaction in the Gran Chichimeca”, en Anne I. Woosley y John C. Ravesloot, eds., Culture and Contact: Charles C. Di Peso's Gran Chichimeca [Dragoon: Amerind Foundation, 1993], 96 y 97). 
DOI: http://dx.doi.org/10.22201/iie.18703062e.2016.109.2580

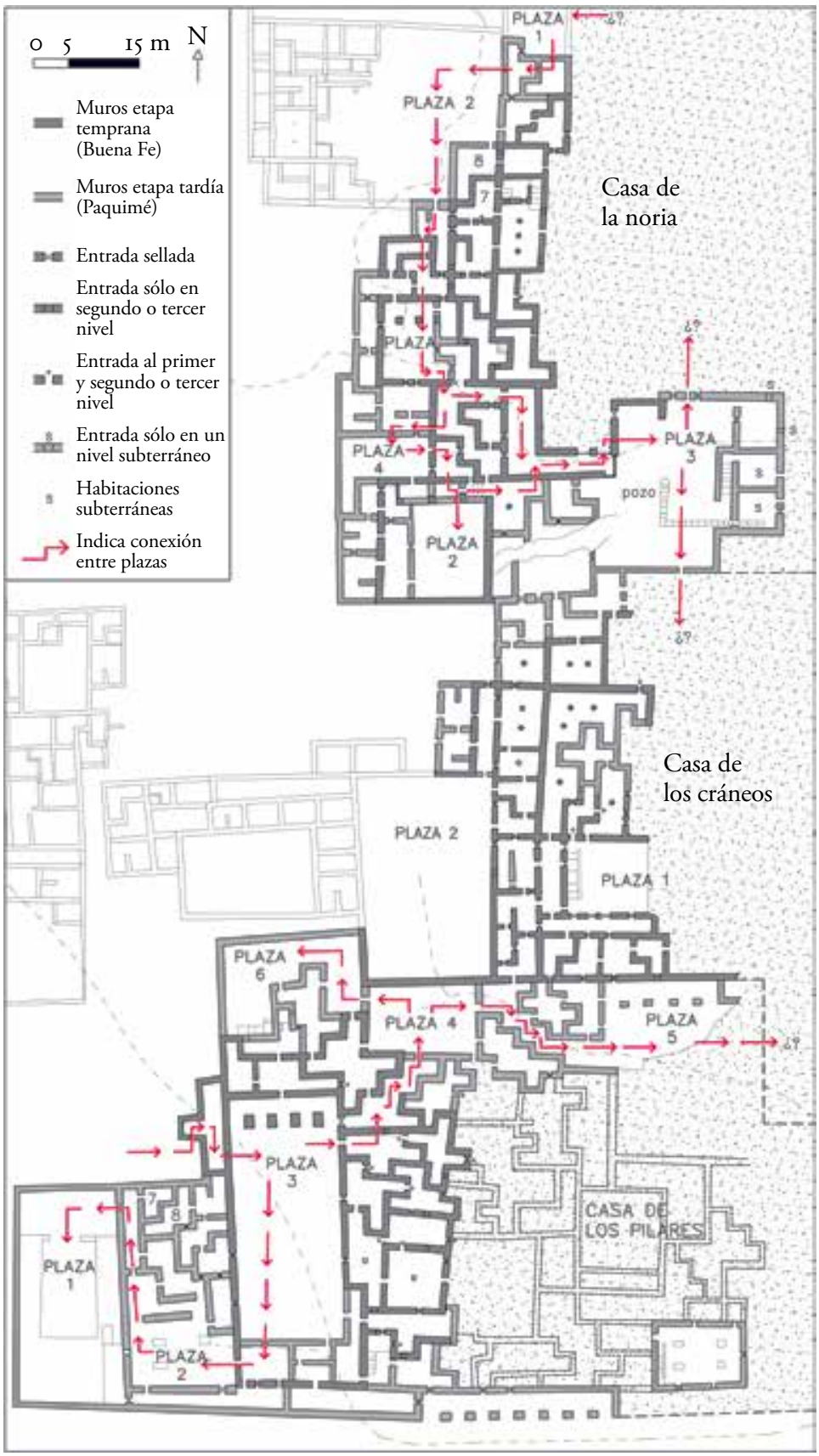


9. Casas Grandes, planta arquitectónica de la Casa de la Noria (Unidad 8), de la Casa de los Pilares (Unidad I4) y de la Casa de los Cráneos (Unidad I6). Se muestran las dos principales fases constructivas del Periodo Medio, conservo entradas selladas tal como los expuso Di Peso. Dibujo: Georgina Parada, a partir del levantamiento y la digitalización de estructuras arquitectónicas realizados por el Instituto Nacional de Antropología e Historia y los planos publicados en Di Peso, Rinaldo y Fenner, Casas Grandes (vid supra, n. I), vols. 4 y 5, 364, 614 y 718.

poseer una función más o menos pública. Algunas de estas últimas tienen forma de largos pasajes angulosos que recuerdan el espacio vacío del mismo elemento pictórico que acabo de mencionar (fig. Io).

La distribución de las plazas provee un indicio para comprender las leyes que rigen el espacio interior de Casas Grandes. Éstas no se distribuyen a partir de un elemento de mayor magnitud considerado troncal o central, lo cual mantendría una estructura arborescente con jerarquías bien definidas, más cercana a nuestra noción funcionalista de orden. Más bien se intercalan entre la compleja red de habitaciones, tornándose cada vez más internas e inaccesibles, dado el elevado número de niveles a transitar para llegar a ellas (en la figura 9 los trayectos entre plazas se muestran con flechas rojas). Lo admirable de esta distribución es que presenta tal grado de volubilidad que cerrar o abrir un solo acceso puede perturbar significativamente el orden: espacios sin proximidad se tornan vecinos, o lo que era inaccesible e interno se vuelve externo y accesible, o viceversa.

Desde este punto de vista el espacio interior en Casas Grandes se acerca a lo que Gilles Deleuze y Félix Guattari llaman rizoma. En oposición a la forma arborescente, en el rizoma no existe un pivote o centro a partir del cual se divida u ordene el espacio, pues se considera una multiplicidad sin relación con la unidad. Cualquier punto, por más diverso que sea, puede conectarse con otro, sin que esté preestablecido por una estructura. Además, puede romperse en cualquier parte sin que esto sea significativo, ya que todas sus líneas remiten constantemente unas a otras, pues no tiene origen ni fin, sino múltiples entradas. ${ }^{24}$ En Casas Grandes cada habitación no está definida por

24. Para el concepto de rizoma me baso en la descripción hecha por Gilles Deleuze y Félix Guattari en la "Introducción” de Mil mesetas: capitalismo y esquizofrenia, trad. José Vázquez Pérez (Valencia: Pre-Textos, 2004), I3-18. 


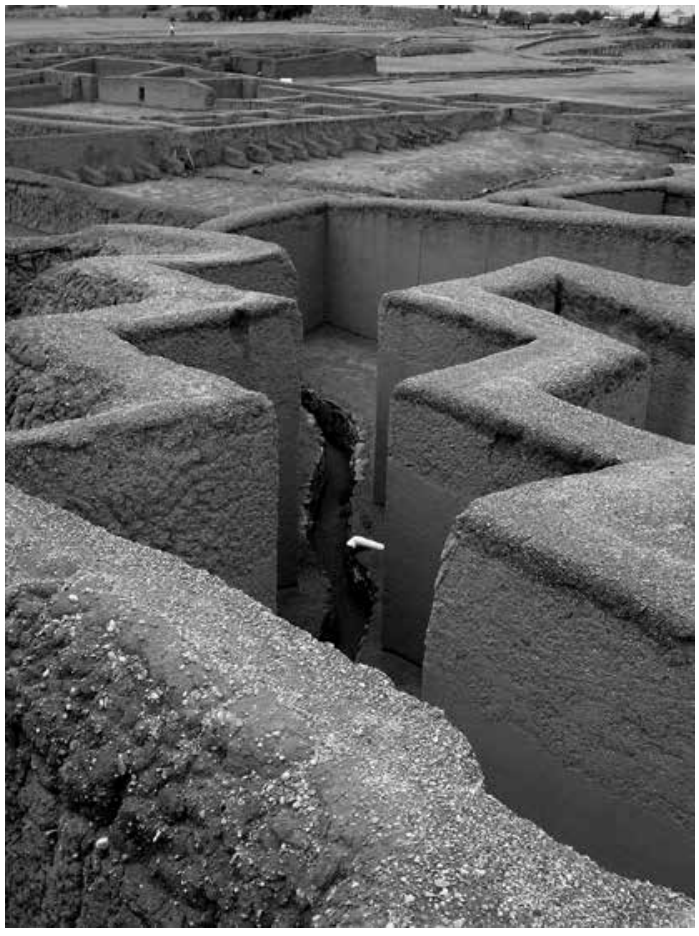

Io. Casas Grandes, Casa de los Pilares. Esta habitación unía las plazas 4 y 5 . Foto: Georgina Parada. Secretaría de CulturaINAH-Méx. "Reproducción autorizada por el Instituto Nacional de Antropología e Historia”.

su relación con un elemento externo a ella (la unidad), más bien se inserta en un contínuum, afectada sólo por los elementos que le anteceden o preceden.

A pesar de su aparente amorfismo, la vivienda no es una masa que creció indistintamente. Sabemos que estuvo en constante transformación durante los años en que fue habitada, pero es posible que durante este proceso se mantuviera un equilibrio. El perímetro del conjunto habitacional guarda cierta igualdad entre la parte norte y la sur, no por medio de una simetría axial (o reflexión especular), sino puntual. Esta última, llamada también "simetría respecto al origen", se da cuando cada parte tiene otra que le corresponde a la misma distancia de un punto central imaginario, pero en dirección contraria. Puede comprobarse al trazar líneas de un extremo a otro en el plano: se verá que las principales salientes de la vivienda tienen su contraparte, girada I8 $0^{\circ}$, del lado contrario (fig. 2). El punto de convergencia se encuentra cerca del famoso pozo subterráneo de Casas Grandes, que Di Peso considera único 
en América. ${ }^{25} \mathrm{~A}$ este pozo, de más de $\mathrm{I} 4$ metros de profundidad, se llega por un pasaje subterráneo desde una habitación a su vez oculta (subterránea), ubicada al sur de la Unidad 8 (Casa del Pozo). Christine y Todd VanPool consideran este elemento como la representación más elaborada de un axis mundi en todo el noroeste, más en concreto, el punto de apertura entre mundos, la conexión entre el agua y Casas Grandes, a la que suponen metafóricamente como una ciudad de agua. ${ }^{26} \mathrm{La}$ existencia de un "centro" parecería contradecir lo antes expuesto. Debo aclarar que este pozo, contenido en el interior de la tierra, es un elemento oculto y vedado; al parecer el ingreso estaba restringido y su ubicación es imperceptible desde las viviendas. Podría decirse que este elemento, aunque omnipresente, está más allá de la dimensión habitable.

\section{La cerámica}

Traducir en palabras la complejidad y riqueza de la composición pictórica de la cerámica parece una tarea imposible en este reducido artículo, he de aclarar que las conjeturas expuestas aquí se basan en un minucioso estudio de cada una de las 45 piezas polícromas que forman parte de mi corpus, entre las que se encuentran ollas, cántaros, cuencos y vasijas-efigie. Todas proceden del sitio arqueológico de Casas Grandes y fueron elegidas debido a que ya sea por observación personal, o por reproducciones realizadas por los arqueólogos, fue posible tener una imagen total de sus diseńos. Presento 20 de ellas (figs. 16-35), la mayoría dibujos de mi autoría, con la esperanza de acrecentar nuestro conocimiento sobre Casas Grandes, puesto que no se encuentran en la publicación de Di Peso.

Un carácter distintivo de esta cerámica es que no parece existir una relación entre formas y diseños con sus diversos usos, conclusión a la que llegué después de examinar con detenimiento el contexto arqueológico de cada pieza. En pocas palabras, las mismas imágenes se plasmaron desde ofrendas funerarias,

25. Di Peso, Casas Grandes, vol. 2, 356. Una descripción explícita del pozo se encuentra en Di Peso, Rinaldo y Fenner, Casas Grandes, vol. 4, 37I-38I; cabe señalar la considerable cantidad de objetos votivos que se encontraron aquí.

26. Christine S. VanPool y Todd L. VanPool, Signs of the Casas Grandes Shamans (Salt Lake City: The University of Utah Press, 2007), 27 y 28. 
DOI: http://dx.doi.org/10.22201/iie.18703062e.2016.109.2580

190

GEORGINA PARADA CARRILLO

hasta aquellas vasijas utilizadas para almacenar o preparar y servir alimentos. ${ }^{27}$ Del mismo modo las diferentes tipologías locales en las que se clasifica la cerámica polícroma de Casas Grandes (mi corpus incluye los tipos Ramos, Babícora, Villa Ahumada y Escondida), distinguidas por la composición de las pastas y cualidades estilísticas, también comparten las mismas concepciones espaciales.

Para atender al análisis que propongo debe tenerse en cuenta que no me baso en semejanzas de formas ni rasgos iconográficos, sino en las articulaciones del espacio pictórico, donde concluí que a pesar de la infinidad de variaciones de un reducido número de elementos, formas y colores, todos los diseños evocan una misma estructura que consiste en una sucesión entre línea quebrada y espiral, en la que cada sección, hasta la mínima, remite a la totalidad. Podrá objetarse que la clasificación mostrada más adelante no es del todo clara y que muchas vasijas fluctúan en otras secciones; sin embargo, de todas las posibilidades consideradas, fue la que arrojó mayores frutos. Esta clasificación es valiosa porque deja de lado la organización espacial cuatripartita y los conceptos de oposición y dualidad bajo los cuales la cerámica de Casas Grandes se analiza comúnmente. ${ }^{28}$

En un primer grupo la superficie se segmenta o articula por medio de una línea quebrada o angulada a lo largo del plano horizontal, y presenta cuatro variaciones: I) los segmentos de la línea quebrada son continuos e iguales (figs. I6-I8); 2) los segmentos están separados y cada uno desarrolla diseños independientes (figs. I9-2I);3) la línea quebrada se repite girada cuatro veces, generando un diseño romboidal (fig. 22); 4) la línea quebrada se separa hasta conformar objetos independientes (fig. 23).

Un segundo grupo comprende aquellas vasijas en las que la primera articulación no se realiza con líneas anguladas, sino curvas. Se presentan como dos helicoidales enfrentadas o como anillos concéntricos (figs. 24 y 25, respectivamente).

En un tercer grupo la línea quebrada, la cual recorre el cuerpo de la olla, no tiene prioridad frente a las espirales (curvas o anguladas) que rellenan el espa-

27. Además de los diseños pictóricos, ningún tipo, forma volumétrica o tratamiento de superficie se utilizó exclusivamente para algún propósito en específico. Véase Di Peso, Casas Grandes, vol. 2, 6Io y 6II; y Di Peso, Rinaldo y Fenner, Casas Grandes, vol. 6, 85 y 86.

28. Véase, por ejemplo, la obra citada de VanPool y VanPool, Signs of the Casas Grandes Shamans, y la de Barbara Moulard, "Archaism and Emulation in Casas Grandes Painted Pottery", en Richard Townsend, ed., Casas Grandes and the Ceramic Art of Ancient Southwest (The Art Institute of Chicago, 2006), 66-97. 
cio sobrante. Por lo cual, espirales y rectas aparecen simultáneamente con tres variantes: I) la recta se enrosca hacia un lado y otro a modo de espiral doble divergente (fig. 26); 2) la línea recta unida a la espiral se sucede continua por toda la superficie; 3 ) la recta y la espiral pueden separarse para formar objetos independientes (fig. 27).

En el último grupo se encuentran aquellas piezas en las cuales el diseño pictórico está condicionado primigeniamente por la forma volumétrica. Pueden articularse a lo largo del plano horizontal cuando la olla tiene forma radial, lo cual presenta segmentos iguales (figs. 28 y 29); o en el plano vertical, que muestra segmentos desiguales, como sucede con las vasijas-efigie (figs. 30-35).

Sobra decir que, posteriormente, cada uno de los segmentos resultantes se articulará de nuevo en una de las operaciones anteriores, y así, hasta que la superficie de la vasija o el equilibrio que buscó el artista muestren pertinente detener la segmentación.

La relación entre el todo y las partes puede darse en distintos grados. En muchos casos es evidente, pues todavía se nota cierta semejanza entre una forma y otra. El ejemplo más claro es la figura escalonada que se construye una y otra vez dentro de sí misma.

Puede ser que la diagonal de la figura escalonada se asocie con las formas espirales de arriba y abajo, y no con la vertical, por lo que adquiere la configuración de una espiral doble divergente, imagen que en ocasiones retorna dentro de ella.

A menudo un proceso compositivo que aparece en cierto nivel no se repite en el diseño de la misma pieza, sino en cualquiera de los niveles de otra vasija. Esto me interesa sobremanera porque sugiere que cada una es parte de un conjunto mayor, de una totalidad.

En otros casos la relación es más compleja y se define mejor como similitud entre sus partes. A diferencia de la semejanza que indica una aserción unívoca y siempre la misma, la similitud multiplica las afirmaciones, y remite más bien a la relación entre las cosas. ${ }^{29}$ La filosofía de la ciencia ha adoptado el término matemático de homomorfismo a fin de desafiar el limitado concepto de semejanza en el arte. Éste parte del supuesto de que puede existir una correspondencia entre dos objetos sin necesidad de una relación de semejanza (en la que se comparten cierto número de propiedades) ni de isomorfismo (donde

29. Michael Foucault, Esto no es una pipa. Ensayo sobre Magritte, trad. F. Monge (Barcelona: Anagrama, 198I), 68. 
DOI: http://dx.doi.org/10.22201/iie.18703062e.2016.109.2580

192

GEORGINA PARADA CARRILLO

los elementos pueden variar mientras se preserve la estructura); pues ellas no constituyen la esencia de la representación, pudiendo existir relaciones más profundas entre un objeto y otro. ${ }^{30}$ Desde el punto de vista matemático, el homomorfismo se refiere a una representación que preserva la estructura entre dos conjuntos algebraicos, sin necesidad de una correspondencia uno-a-uno, es decir, que no todos los elementos de un conjunto A deben ser necesariamente proyectados en un conjunto B. ${ }^{3 \mathrm{I}}$ Esto requiere que haya correspondencia entre las propiedades (simetría/asimetría, reflexividad/irreflexividad) y las operaciones (relaciones entre los elementos) de los dos conjuntos; aunque no sea necesario que se mantengan las mismas operaciones, por ejemplo, la adición puede proyectarse en multiplicación. ${ }^{32}$ De esta manera es posible ampliar las relaciones de oposición a las que alude Foucault (lo que está a la derecha, está a la izquierda; lo que está arriba, está abajo; lo que está oculto, está visible), por medio de un juego donde las propiedades de la forma de un conjunto no sólo reaparecen -invertidas o no- en las formas del otro, sino en el modo en el que se articulan dichos elementos. Al tomar ejemplos de la cerámica aquí estudiada obtenemos la similitud que existe entre una línea recta, articulada por elementos curvos y una línea curva, articulada por elementos rectos, o lo que es lo mismo. O la relación entre una línea recta continua articulada por elementos angulares discontinuos y elementos angulares discontinuos, articulados cada uno mediante una línea recta continua.

La policromía de la cerámica de Casas Grandes se limita al uso de dos pigmentos sobre la pasta o el engobe, de modo que en cada pieza sólo se presentan tres colores, a menudo ubicados dentro de las variaciones de un tono rojizo o café: el claro, que va de crema a ocre; el medio, que presenta un rojo más oscurecido o cobrizo que el rojo puro; y el oscuro, que varía de café a negro, es decir, que las diferencias se perciben en la categoría de intensidad luminosa, más que de tonalidad. Tan sólo el análisis de esta tricotomía podría abarcar un estudio independiente, me restrinjo a exponer los tres usos principales que identifiqué, los cuales pueden convivir en una misma pieza. I) el

30. Mauricio Suárez, "Scientific Representation: Against Similarity and Isomorphism", en International Studies in the Philosophy of Science 17, núm. 3 (2003): 230. Aunque el autor se refiere al problema de la representación en el campo científico, otros estudiosos como Chiara Ambrosio lo han transportado al ámbito de la historia del arte.

3I. Chiara Ambrosio, "Iconicity as Homomorphism: The Case of Picasso's Guernica", Ideas in Action, Nordic Studies in Pragmatism I (Helsinki: Nordprag, 20I0), I57.

32. Ambrosio, "Iconicity as Homomorphism", I57. 
rojo designa o limita el borde de la vasija (figs. 27, 28, 33, 35) o una sección del espacio pictórico (figs. 2I y 22), mientras el resto del diseño puede o no hacer uso de dicho color. Dejo abiertas las posibilidades de que en este caso el rojo pueda sugerir tanto una abertura, como delimitar el espacio de manera más incisiva, es decir ideal, absoluta; ${ }^{33}$ 2) el rojo y el negro rellenan superficies distintas. Aquí los dos colores tienen la función de acentuar la diferencia entre dos elementos que por su propia forma ya eran disímiles. Esto produce los muy conocidos juegos ambiguos entre fondo y figura; característicos de esta cerámica, pues un color puede intervenir como figura en relación con uno o como fondo en relación con el otro (figs. 23, 27 y 29); 3) el rojo y el negro rellenan superficies semejantes. En este caso los dos colores mantienen la misma relación con el fondo, su uso tiene la función de diferenciar espacios que parecían iguales (figs. 17, 19, 26, 32).

Ahora el artista no sólo cuenta con las variaciones entre formas escalonadas y espirales para diferenciar, sino que se vale del color para construir distintos intervalos compuestos. Al advertir esta vinculación o más correctamente "indisociabilidad" entre forma y color, ${ }^{34}$ la novedosa incursión de policromía en la cerámica (que vimos está ligada a un momento histórico) no emerge como un simple agregado a los diseños, sino que éstos son impensables sin la intervención de tres colores; especialmente me refiero al Ramos polícromo que equipara en número al corpus de estudio (33 piezas). ${ }^{35}$ Es sugerente que a pesar de que existen piezas de este tipo que carecen de rojo, siempre se recurre a un tercer término conformado por un entramado negro-crema.

También se observó que el borde rojo podía delimitar o contener el espacio biese articulado a su vez por los tonos antagónicos oscuro-claro. Si se concibiésemos una analogía con la composición espacial antes vista, donde se

33. "El artista aísla el espacio para definirlo como una totalidad, como una unidad independiente y autosuficiente. El marco mismo significa al espacio, no sólo lo delimita, sino que lo nombra y define”, Dúrdica Šégota, Valores plásticos del arte mexica (México: Universidad Nacional Autónoma de México-Instituto de Investigaciones Estéticas, I995), IO2.

34. La "indisociabilidad absoluta" entre volumen, línea y color ha sido planteada por la misma historiadora en el arte mexica, donde descubre una relación intencionada y significativa en el modo en que el artista articula estos elementos con el fin de matizar o subrayar contrastes plásticos (Š́egota, Valores plásticos del arte mexica, I2I y I22).

35. Me tomo la libertad de acudir a esta tipología como modelo, pues se considera el tipo por excelencia y culminación de la cerámica de Casas Grandes, además, tipologías de antigüedad mayor como Villa Ahumada y Babícora, que también forman parte de mi corpus, adquirieron características propias del nuevo tipo Ramos como el delineado de las superficies rojas con color negro. 
DOI: http://dx.doi.org/10.22201/iie.18703062e.2016.109.2580

194

GEORGINA PARADA CARRILLO

II. Casas Grandes, urna funeraria tipo Ramos polícroma. Museo Nacional de Antropología. Foto: Diego Flores Olmedo. Secretaría de Cultura-INAHMéx. "Reproducción autorizada por el Instituto Nacional de Antropología e Historia”.

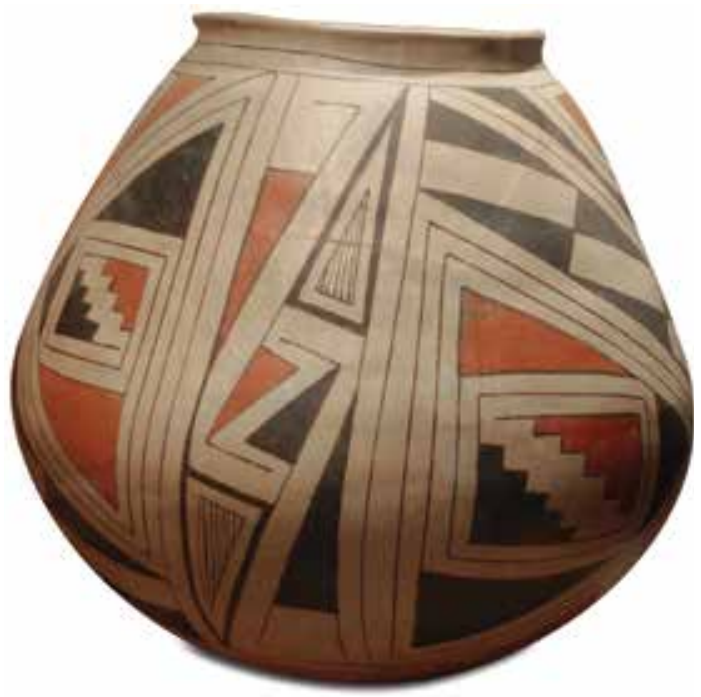

planteó una sucesión infinita, en la que cada parte remite a la totalidad, y donde un elemento con el mínimo de articulaciones repite la estructura de uno con mayor número, es posible suponer que el uso de los tres colores implica plenamente estos conceptos, pues el rojo (con relación a los otros dos, no por sí mismo) insinúa nuevas articulaciones inclusive en elementos que carecen de segmentación. Es significativo que las superficies demasiado grandes siempre se rellenan de rojo, nunca de negro ni crema (figs. 20, 23), como si este espacio no necesitara más segmentación al ser un elemento híbrido.

Al observar con detalle el diseño de cada pieza se descubre un número de particularidades en sumo reveladoras; lamentablemente me vi en la necesidad de exponer tan sólo una. Se trata de una gran olla de cuerpo curvo-convergente y base convexa exhibida en el Museo Nacional de Antropología, que guardaba los restos de un posible gobernante, dentro de una habitación oculta en el Montículo de las Ofrendas (Unidad 4) (figs. II y 19). Su composición sorprende por el rigor geométrico, pues carece de toda imagen figurativa. Conforme se examina esta pieza la aparente heterogeneidad de sus formas se traduce en una sobria armonía organizada con precisión matemática. Su diseño pictórico se sometió al método de clasificación antes descrito, con el fin de obtener la desarticulación de sus partes (fig. I2). Indico con la letra $A$ (mayúscula 


\section{Conjunto}
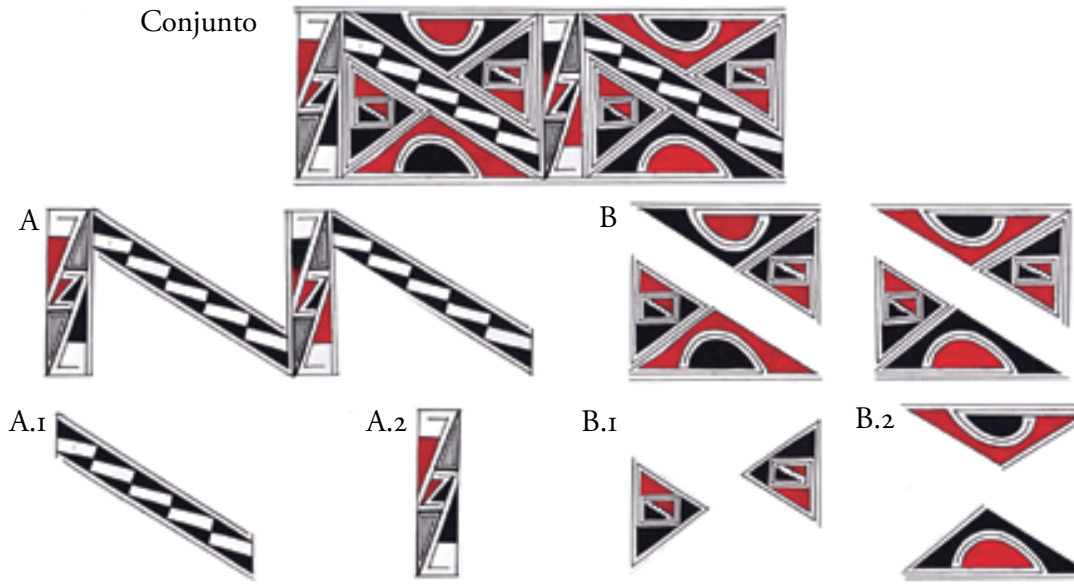

B.I

B.2
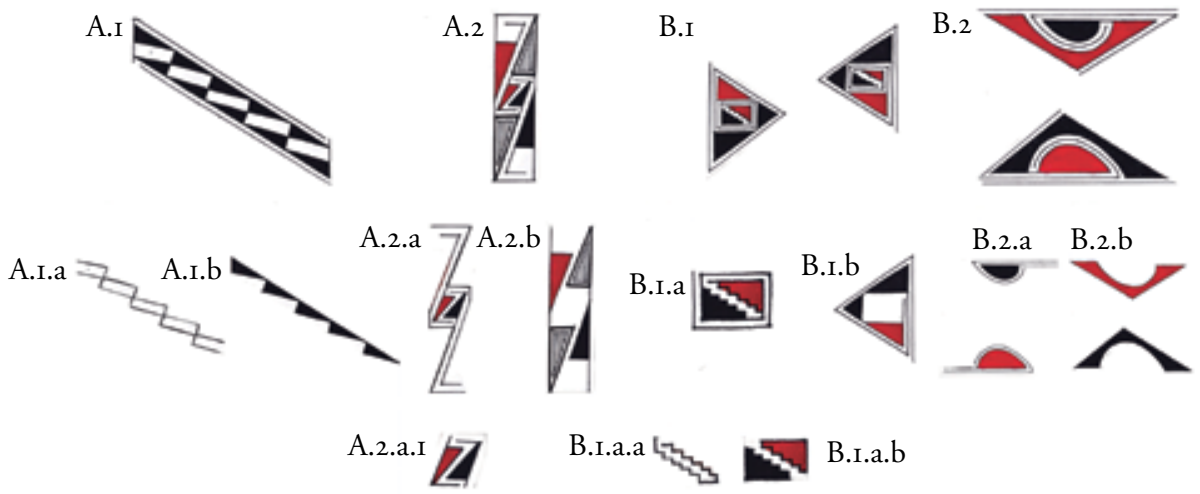

I2. Segmentación del diseño pictórico de una vasija de Casas Grandes (fig. II). La letra $a$ indica los elementos angulados que dividen el espacio, la letra $b$, los espacios que resultan de dicha segmentación. Los números indican variaciones del mismo elemento. Tabla: Georgina Parada.

o minúscula) los elementos quebrados o angulados que dividen el espacio en dos, y con la letra $B(b)$ los espacios que resultan de dicha segmentación. Los números I y 2 indican si hay variaciones del mismo elemento.

Este método permite observar claramente las correlaciones entre las partes. Así se obtiene que la banda quebrada A corresponde con A.2.a y en cierta medida con A.I.a. El subconjunto B reaparece en A.r.b y A.2.b, pues los tres poseen triángulos escalenos sucedidos uno tras otro, con su repetición girada $180^{\circ}$. El conjunto completo (A-B) puede encontrarse tanto en A.2, como en A.2.a.I.

¿Qué sucede con las figuras triangulares constantes en toda la cerámica? Si se observa el grupo B.I, la división en nuevos triángulos no es simultánea, surgen a lo largo de la banda blanca que se enrosca en espiral. Si se imagina esta figura desenrollada no es más que el mismo elemento quebrado con formas 
DOI: http://dx.doi.org/10.22201/iie.18703062e.2016.109.2580

196

GEORGINA PARADA CARRILLO

13. Casas Grandes, olla tipo Ramos polícroma.

Bodegas del Museo de las

Culturas del Norte. Foto:

Georgina Parada. Secretaría de Cultura-INAH-Méx.

"Reproducción autorizada por el Instituto Nacional de

Antropología e Historia”.

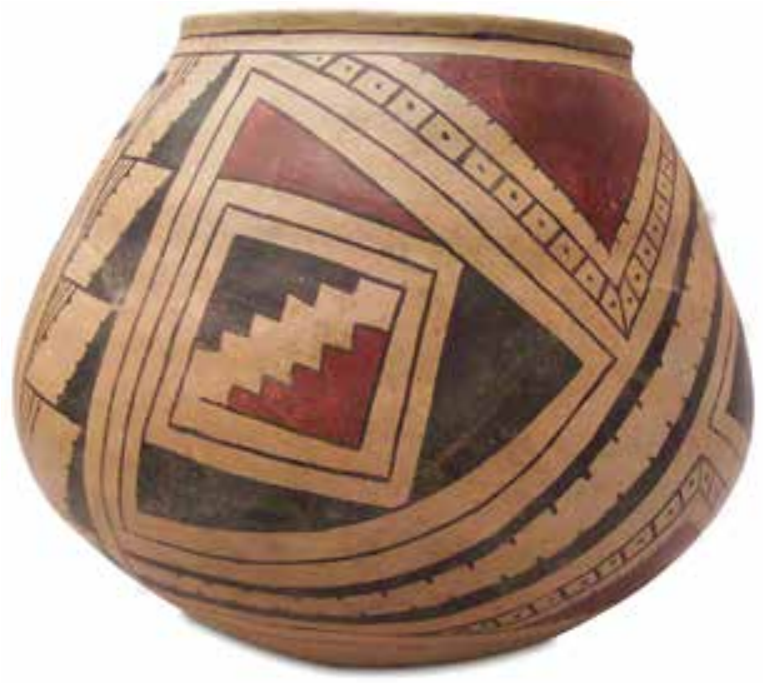

angulares en su interior, de modo que, bandas quebradas y triángulos se segmentan por la misma sucesión de pequeños triángulos, pero su diferencia reside en el movimiento. En el primer caso los triángulos se proyectan hacia los extremos, en el segundo, se configuran en espiral hacia el interior (o del interior hacia afuera).

Un vistazo a otras vasijas muestra cómo las articulaciones de $A$ y $B$ admiten una serie de variantes sin perder la esencia de su estructura (fig. I3). Por ejemplo, la sucesión de triángulos, que aparece dentro de las bandas quebradas, puede intercambiarse por círculos, líneas, formas escalonadas o espirales dobles (figs. I6, 20, 2I y 35, respectivamente), conservando la misma idea de ritmo; o bien, las espirales curvas pueden volverse angulosas (fig. 22).

Parte de la perfección que le atribuyo a esta pieza (fig. II) es una característica que no he encontrado en ninguna otra. En ella los dos triángulos cercanos a la boca no son idénticos, lo mismo sucede con los contiguos a la base, mantienen la forma pero los colores se invierten. La imagen idéntica surge cuando se gira $180^{\circ}$, por lo cual presenta una simetría puntual, descrita en la sección de la arquitectura, que aparece tanto en sentido longitudinal como transversal (en $\mathrm{B}$, de la figura I2, los dos triángulos superiores mantienen esta simetría con los inferiores; o bien, los dos de la derecha con los de la izquierda). Esta simetría es propia de la greca escalonada. En un exhaustivo trabajo sobre la composición gráfica de este elemento se muestra cómo la figura y su repetición 
producida automáticamente como fondo no mantienen un eje de simetría sobre el plano, lo cual produciría una imagen tipo espejo, sino que proviene de una tercera dimensión que lo atraviesa, es un eje de rotación..$^{36}$ Una imagen creada de esta manera mantiene tal cual el orden de sus partes, pero cambia su dirección. No es insignificante que esta simetría encuentre su construcción plena en una superficie convexa, casi esférica, como la olla. En una esfera cada punto presupone, sin excepción, su antípoda, es decir, un punto diametralmente opuesto. La repetición de diseños girados $180^{\circ}$ en toda la cerámica de Casas Grandes parece responder a esta propiedad intrínseca del soporte. En esta vasija se presenta una simetría asombrosa, pues cada elemento atraviesa su centro real, el del espacio contenido, y reaparece invertido en el otro lado. De nuevo nos encontramos con un centro invisible sobre la superficie, pero que domina silenciosamente la composición en su totalidad.

Ya mencioné que cada segmento del diseño está sujeto a las mismas leyes, por tanto, la simetría puntual se repite en todos los niveles. En una escala más pequeña el centro imaginario se transfiere del interior del volumen a la superficie (por ejemplo, A.2 de la figura 32). La imagen, al repetirse, puede conservarse idéntica o admitir las más ingeniosas variaciones, mientras se mantenga la relación de homomorfismo que describí con anterioridad.

No existe un solo elemento en sus diseños que pueda aislarse de la totalidad. Aquéllos se entrelazan unos con otros formando caminos que se enrollan hacia distintas direcciones, vinculándose en un orden muy distinto al de su ubicación sobre la superficie de la cerámica, si ésta se piensa como un sistema de coordenadas. En otras palabras, la relación entre los objetos deviene más significativa que el propio objeto representado. Obsérvese la imagen más característica de la cerámica a la que ya hice mención: los dos elementos escalonados, negro y rojo, inscritos en un rectángulo. Pictóricamente se representa de dos modos distintos: uno en el que las dos figuras escalonadas se unen con la misma greca o espiral que los rodea, y otro en el que cada una se relaciona con una espiral independiente (las vasijas de las figs. 16 y 25 presentan ambas versiones). En arquitectura también se vio cómo estos elementos pueden o no estar conectados.

Antes de terminar con la pieza elegida, muestro un ejercicio que no obstante su simpleza sorprende por la trascendencia de los resultados. Me refiero a la proyección polar de la olla en vez de la proyección longitudinal que había utilizado,

36. Mauricio Orozpe Enríquez, El código oculto de la greca escalonada (México: Escuela Nacional de Artes Plásticas, 2010), 39. 
DOI: http://dx.doi.org/10.22201/iie.18703062e.2016.109.2580

198

GEORGINA PARADA CARRILLO

I4. Proyección polar de una vasija de Casas Grandes (fig. 3I). Se

observa cómo la banda escalonada se transforma en dos curvas. Dibujo:

Georgina Parada.

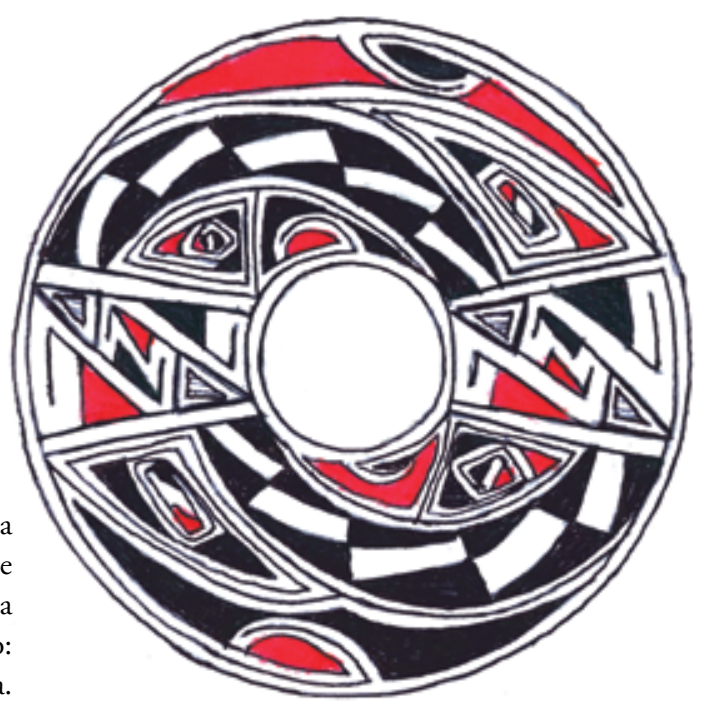

con el fin de observar qué pasaría si el diseño no se mirara por medio de un recorrido lineal, sino desde el centro superior hacia afuera, como se muestra en la figura I4. Encontré que la banda escalonada que recorre toda la superficie no es más que la figura formada por dos curvas opuestas (a manera de dos letras P invertidas) tal como aparece en otras piezas (figs. 17, 25). Stricto sensu se trata de dos helicoidales (curva en tres dimensiones) divergentes, pues geométricamente el espacio pictórico de la vasija es una superficie curva bidimensional. ${ }^{37}$ En un espacio de tales características cada recta (camino más corto entre dos puntos) es en realidad la línea de menor curvatura, la sección de un círculo máximo o geodésica. Debido a que la curvatura de la vasija no es homogénea, toda línea (mientras no sea absolutamente horizontal), en vez de ser un semicírculo, será sin excepción una espiral o hélice. Este hallazgo, en apariencia simple, tiene significativas repercusiones y resulta imprescindible tenerlo presente al atender las conclusiones; demuestra que las diferencias y semejan-

37. Esta superficie es un ejemplo de la llamada geometría elíptica o riemanniana que consiste en un modelo de geometría no euclidiana, ya que no satisface el quinto postulado de Euclides, pues las paralelas sí convergen en un punto. Aquí, todas las rectas son arcos de un círculo máximo, y aunque pueden extenderse indefinidamente, tienen longitud finita. Al igual que la línea, punto y superficie son entidades distintas a las de la geometría plana. 
zas entre formas curvas y escalonadas sólo existen con relación al punto donde se transfiere la visión.

No toda la cerámica de Casas Grandes ostenta el mismo grado de estilización. Son conocidas sus vasijas de formas humanas, animales e inclusive vegetales; y la representación bidimensional de animales restringida exclusivamente a aves y serpientes..$^{38} \mathrm{La}$ articulación de estas piezas responde a las mismas leyes de la vasija antes vista, siempre se presentan las correspondencias entre el todo y las partes, sin excluir elementos figurativos como animales o rostros humanos.

El diseño de estos últimos se configura con las mismas prácticas de variación entre formas curvas y anguladas, e introducción de ritmos y direcciones. En la vasija-efigie femenina (figs. I5 y 30) la pintura facial se conforma por dos bandas con puntos intermitentes, las cuales no discrepan mucho de la banda con círculos de otras piezas. La gran diferencia del diseño de los rostros radica en que presentan una simetría bilateral (reflexión especular) propia de la naturaleza y no puntual, la cual abunda en la mayor parte de los diseños de Casas Grandes y en cierto grado es poco natural. ${ }^{39} \mathrm{La}$ simetría bilateral nunca aparece sobre la superficie lisa de la vasija, sólo en las que tienen un modelado tridimensional, como cabezas animales y humanas, aunque apenas estén sugeridas como en la figura 33. Por alguna razón significativa la simetría puntual (giro de $180^{\circ}$ ) es "indisociable" del volumen no articulado, del espacio indefinido; la bilateral, del espacio articulado o definido.

No creo que haya una intención de retratar o evocar el rostro o el cuerpo humano, tal acercamiento puede ser mejor expresado como un devenir-hombre, pues la vasija toma algo de éste sin perder sus cualidades propias. ${ }^{\circ} \mathrm{Con}-$

38. Como lo menciona Di Peso, es posible que otros diseños zoomorfos estén presentes en algunos fragmentos, pero son demasiado incompletos para comprobarlo (Di Peso, Rinaldo y Fenner, Casas Grandes, vol. 6, 283).

39. Basta intentar hacer los mismos movimientos con el brazo derecho e izquierdo, pero girados $\mathrm{I}^{8} \mathrm{O}^{\circ}$, para percatarse de lo difícil que es. En cambio compárese con la relación que Franz Boas establece entre los abundantes diseños con simetría vertical y los movimientos simétricos del cuerpo determinados psicológicamente; no porque las imágenes se realicen con ambas manos, sino porque están en concordancia con una sensación motora (Franz Boas, Primitive Art [Nueva York: Dover, 1995], 33).

40. Para Deleuze y Guattari devenir es un proceso de aproximación, que no busca imitar, identificar o proporcionar relaciones formales con el objeto: "Devenir es, a partir de las formas que se tiene, del sujeto que se es, de los órganos que se posee o de las funciones que se desempeña, extraer partículas, entre las que se instauran relaciones de movimiento y de reposo, de velocidad y de lentitud, las más próximas a lo que se está deviniendo, y gracias a las cuales se de-viene”, 
DOI: http://dx.doi.org/10.22201/iie.18703062e.2016.109.2580

200

GEORGINA PARADA CARRILLO

15. Casas Grandes, vasija-efigie tipo

Ramos polícroma. Museo de las

Culturas del Norte. Foto: Georgina

Parada. Secretaría de Cultura-INAH-

Méx. "Reproducción autorizada por el Instituto Nacional de Antropología e Historia”.

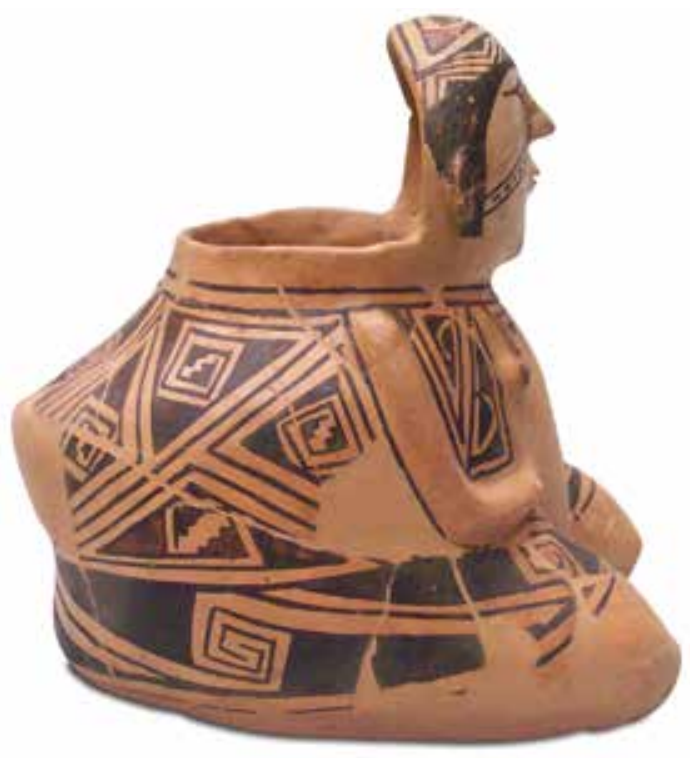

clusiones semejantes pueden hallarse en los elementos zoomorfos. Dentro del triángulo opuesto al rectángulo con escalera doble a menudo aparece una imagen semejante a un pájaro, o aquella interpretada como cabeza de guacamaya. Este devenir-ave puede estar en distintos grados de estilización. En algunos casos la figura es independiente del exterior (las patas del pájaro de la fig. 2I están separadas de las bandas concéntricas, pero en cierta medida las evocan), en otras se fusiona con las formas espirales de las cuales proviene (fig. 34), es decir, aparece ligada a los elementos que antecede o precede, es un instante temporal entre el continuo juego entre dos movimientos disímbolos: el que se proyecta a los extremos y el que se desarrolla hacia el interior.

Podrá objetarse que existen animales representados de modo relativamente realista. La figura 24 contiene una imagen muy exacta del coralillo falso, ¿̨buscaba el artista evocar al animal en sí?, lo creo muy poco probable, pues se sabe que la mayor parte de las serpientes de la cerámica no corresponde a especies del mundo natural. ${ }^{4 \mathrm{I}} \mathrm{La}$ razón de que dicha serpiente esté representada, y no

Deleuze y Guattari, "I730-devenir-intenso, devenir-animal, devenir-imperceptible”, en Mil mesetas. Capitalismo y esquizofrenia, 275.

4I. VanPool y VanPool, Signs of the Casas Grandes Shamans, 90. 
otras, tal vez responde a que el maravilloso diseño de su piel (triángulos rojos y negros enfrentados y separados por bandas blancas) se aproxima asombrosamente a la plástica de su cerámica.

¿Qué sucede con la representación de la figura humana? Tengo conocimiento de una sola pieza en la ciudad de Casas Grandes que exhibe una figura bidimensional de un hombre (fig. I8). ${ }^{42}$ VanPool la considera una posible representación de un chamán o sacerdote en proceso de metamorfosis. ${ }^{43} \mathrm{Sin}$ intención de discutir su hipótesis, me interesa reiterar su forma: el torso es una figura alargada donde se suceden tres imágenes parecidas al signo de numeral (\#) con un círculo al centro (a su vez esta figura se encuentra invertida en los triángulos inferiores, el círculo "contenido" se vuelve "contenedor"), los brazos, a manera de banda, ciñen dos espacios triangulares opuestos, el perfil de la cabeza es una línea escalonada, y, por último, el tocado no es más que una espiral fusionada a la cabeza escalonada.

No niego que estas imágenes sean inequívocamente hombres, aves y serpientes, pero dudo que su verdadera intención fuese aludir a ellas, pues no retratan una existencia previa, sea real o imaginaria. A propósito del caracol, Paul Westheim cuestiona si el uso reiterado de este ornamento en el arte precolombino se justifica, no en el objeto mismo, sino en la formación extraordinaria que posee. ${ }^{44}$ Wilhelm Worringer, más directo que su alumno, opina simplemente: "el ornamento vegetal (en este caso cualquier elemento natural) no reproduce originalmente la planta misma sino la ley a que está sujeta su formación exterior." 45 Habría que preguntarse más bien por qué estos elementos son depositarios de los principios trascendentales que el arte de Casas Grandes eternizó. Pero dichos elementos sólo se utilizan cuando se cumplen ciertas condiciones dentro de un sistema. Resulta revelador que la cerámica exhiba un repertorio considerable de animales representados volumétricamente, como felinos, tortugas, osos, marsupiales, peces, roedores o lechuzas; pero

42. Di Peso menciona II fragmentos donde aparecen figuras humanas, lamentablemente los ejemplos que muestra son muy pequeños. Sin embargo, en uno de ellos sí es posible distinguir dos siluetas humanas invertidas (Di Peso, Rinaldo y Fenner, Casas Grandes, vol. 6, 284 y 285).

43. Christine S. VanPool, "The Shaman-Priests of the Casas Grandes Region, Chihuahua, Mexico", American Antiquity 68, núm. 4 (2003): 705.

44. Paul Westheim, Arte antiguo de México, trad. Mariana Frenk (México: Era, 1970), I77.

45. Wilhelm Worringer, Abstracción y naturaleza, trad. Mariana Frenk (México: Fondo de Cultura Económica, 1953), 68. 
que no figuren en dos dimensiones, reservadas tan sólo a aves y serpientes. ${ }^{46}$ A esto puedo agregar que formas de estructura radial, como calabazas y cruces, no se representan en dos dimensiones, pero sí en volumen (fig. 29). ¿Qué estructura y leyes internas veían en estos objetos que cumplieran las necesidades compositivas en una dimensión pero no en otra; y viceversa? Por obvias razones, el volumen de la cerámica sí acepta la simetría radial y axial, y por tanto, a los animales y objetos con dicha simetría, pero vimos que la superficie sin articulaciones respondía a otras necesidades. La serpiente es poco identificable de frente, su mayor expresividad se percibe de perfil o desde arriba, es decir, desde su vista asimétrica. Del mismo modo el ave, al carecer de cuatro patas, produce un perfil asimétrico, donde la redondez de la cabeza se contrapone a la rectitud del cuerpo y cola, más acorde a los diseńos ostentados sobre la superficie no articulada.

La aproximación de estos animales con escaleras y espirales no puede explicarse por simple semejanza formal, pues ni un ave posee aquellas formas, ni precisamente una serpiente, ya que las adquiere sólo por medio del movimiento. Este concepto devela la verdadera relación entre las imágenes figurativas en la cerámica y los famosos montículos "zoomorfos" (figs. If, g y h), cuya identificación como indiqué, es incierta, pero también se reducen al movimiento.

En un principio se dijo que la composición pictórica de la cerámica destacaba por la falta de centralidad. En realidad posee innumerables centros, si se considera que todos los diseños invertidos $180^{\circ}$ se generan a partir de un centro imaginario. Esto evoca en cierta medida el trazo de algunas espirales, pues cada sección de arco deriva de distintos focos (recuérdese que todas las líneas sobre la cerámica son espirales o hélices). La consecuencia inmediata que observo es la evasión o la indiferencia a englobar un espacio único, ya sea terrestre o imaginario, donde pueda darse el acontecimiento. Al carecer de un punto regulador, desaparece todo orden jerárquico entre elementos pictóricos, además de disolver el contraste entre lo externo y lo interno. Por supuesto la

46. VanPool cuestionó seriamente el problema de los animales representados en la cerámica, ¿por qué hay animales importantes que no están representados, por qué algunos que no existen en Paquimé son comunes en la cerámica, o por qué se combinan representaciones de animales reales e imaginarios?, problema que desarrolla a partir de su hipótesis sobre la distinción entre lo local y lo exótico (VanPool y VanPool, Signs of the Casas Grandes Shamans, 20 y 2I). Moulard indica que muchos de los animales representados bidimensionalmente en la cerámica de Mimbres (Nuevo México) sólo se reinterpretaron en Casas Grandes en tres dimensiones, mas no en dos (Moulard, "Archaism and Emulation", 78). 
vasija tiene un sólo centro volumétrico, pero mantiene la misma distancia y relación con cualquier punto de la superficie, por tanto, sólo reitera la igualdad entre términos.

También existen los bordes de la vasija que definen el espacio pictórico como una totalidad, pero es posible que no indiquen un límite o final. En la mayoría de los diseños las bandas blancas (o líneas negras, según se prefiera ver), enroscadas en espiral, se cortan cuando llegan al borde superior o inferior, simulando propagarse hacia un espacio imposible de representar, vinculándose quizá, con el lado contrario. Puede apreciarse mejor en la figura I4, imagen que ha revelado que sus diseños tienen múltiples realidades: son proyecciones distintas de una idea mayor, restringida a una superficie que necesariamente presenta un borde o límite en la boca de la vasija; del mismo modo que un cuadrado, un rectángulo o un hexágono son proyecciones reducidas de un cubo.

Es probable que los creadores de estas piezas no concibieran una separación tajante entre lo que nosotros clasificamos como dimensiones del espacio, pues las combinan indistintamente: los puntos nunca son adimensionales, pues siempre se suceden formando líneas; éstas juegan ambiguamente con el fondo confundiéndose con un elemento de dos dimensiones; y las superficies se ven afectadas por la tridimensionalidad de la olla. En otras palabras todo elemento pictórico participa de una dimensión mayor a él.

\section{Conclusiones: correlación entre el diseño pictórico y la arquitectura}

Este ensayo develó cómo la plástica de Casas Grandes se sujeta a la unicidad espiral-escalera. Westheim ve en estos dos elementos formales dos movimientos antagónicos, ${ }^{47}$ en Casas Grandes los dos elementos no operan uno frente a otro, sino que evocan un punto de contacto. Ambos son construcciones lineales que pueden continuarse al infinito por cualquiera de sus extremos sin perder la esencia que los define: una sección cualquiera contiene la forma del todo. Oscilan entre dos dimensiones, pues abarcan virtualmente una superficie o un espacio volumétrico sin necesidad de delimitarlo. Se distinguen en que los ángulos o segmentos de curva de la espiral giran siempre en la misma dirección, mientras que en la escalera se alternan entre dos direcciones.

47. Westheim, Arte antiguo de México, 168. 
La forma espiral y la escalonada son proyecciones distintas de lo mismo, ${ }^{48}$ expresan diferencias transitorias, no oposiciones; significado reiterado tal vez con el cromatismo de la cerámica. Si en la greca escalonada mesoamericana la fuerza destructora de la espiral empuja la ascensión de la escalera "hacia el nivel de donde partió", 49 en Casas Grandes esta alternancia de fuerzas se traslada a un nivel inusitado. Cuando la espiral termina continúa desde su extremo la nueva línea escalonada, y de ésta emerge una nueva espiral. Del mismo modo no hay antagonismo cuando los peldaños de una figura escalonada pueden configurarse por medio de espirales. Estamos ante una imagen que se contiene infinitamente, aunque pueda tomar diversas formas. Es, de manera simultánea, contenido de un elemento mayor y contenedor de uno menor; una construcción fractal que no obedece a semejanzas, sino a similitudes más profundas. En vista del peculiar modo de llevar a cabo este concepto habría que repensar la aserción de Braniff sobre la posibilidad de que la greca escalonada en el norte de México haya conservado un sentido más cercano al original, ya perdido en Mesoamérica, ${ }^{50}$ aunque no menciona cuál podría ser. Al menos en Casas Grandes espiral y forma escalonada se presentan como variaciones de un mismo tema, contenidas una dentro de la otra, cuyas diferencias radican, si se me permite la expresión, en la "relatividad" del movimiento del observador. ${ }^{51}$

Uno de los primeros aspectos que destaqué en el urbanismo fue la alineación de elementos arquitectónicos, especialmente aquellos montículos que se sucedían a ritmo y espaciamiento constante, como las estaciones en una procesión. Estos elementos se extienden de manera indefinida sin intención de envolver un espacio o evocar imágenes específicas desde determinadas ubicaciones estáticas. En su lugar, establece un dinamismo, donde el movimiento se superpone al acontecimiento sujeto a un espacio físico. Dentro de los elementos que componen esta "procesión" no están excluidos aquellos que se hallan

48. Por ejemplo, la proyección transversal de una hélice cónica es una espiral, mientras que la longitudinal toma la apariencia de una escalera que se dilata o contrae. Lo mismo puede decirse de la hélice esférica.

49. Westheim, Arte antiguo de México, 168.

50. Beatriz Braniff, "Greca escalonada en el norte de México", Boletín del Instituto Nacional de Antropología e Historia, núm. 42 (1970): 40.

5I. Un presupuesto básico de la relatividad es que el estado del objeto (longitud, intervalo temporal) es relativo al estado de movimiento del observador, "el espacio y el tiempo son cantidades dinámicas: cuando un cuerpo se mueve, o una fuerza actúa, afecta la curvatura del espacio y del tiempo, y, en contrapartida, la estructura del espacio-tiempo afecta al modo en que los cuerpos se mueven y las fuerzas actúan” (Stephen Hawking, Historia del tiempo [Barcelona: Planeta, I992], 56). 
fuera de la ciudad propiamente dicha, como la estructura espiral sobre el cerro; de hecho ¿no son los mismos cerros y atalayas, así como su sistema de comunicación, parte del mismo concepto de sucesión trasladado a un mayor tamaño? 52 Esta representación va más allá de la simple recreación de una geografía física, el que se encuentre en otras manifestaciones artísticas demuestra sus raíces en las categorías profundas del pensamiento. Regresando a los pequeños elementos repetidos a lo largo de las bandas quebradas de la cerámica, además de enfilarse en una diagonal, ¿no indican la misma predominancia de movimiento y ritmo dentro de un elemento, la greca escalonada, cuyos ángulos ya contienen estas nociones?

A diferencia de las estructuras públicas que crecen y se proyectan hacia el exterior, en la vivienda los espacios también se suceden uno a otro, pero se dirigen hacia un punto cada vez más interno. Respecto a otro de los procesos compositivos de la pintura: los triángulos, que a su vez se segmentan en nuevos triángulos, siguen un orden de sucesión también en dirección al interior. Las diferencias observadas al confrontar el espacio público y el habitacional (abierto/cerrado, libre/rígido, disperso/comprimido) no son tan amplias si se subyugan a la noción de movimiento. Recuérdese el descubrimiento en la figura 34, con tan sólo cambiar la dirección de la mirada, lo cual es posible traducir al espacio habitable: si me muevo acorde a mi entorno, éste se percibirá como un espacio continuo, símil; si el movimiento no es el mismo que el de mi exterior, éste aparecerá discontinuo, opuesto.

Cabría recordar la organización descentralizada tanto del urbanismo como de la cerámica, pues es una característica clave para entender la relación entre los dos modos de concebir el espacio. Los elementos plásticos se desenvuelven sin acatar leyes propias de la organización espacial, conceptos como arriba/ abajo, lejos/cerca, periférico/central, se vuelven inútiles para definirlos. Por el contrario está la predominancia de adverbios temporales como antes/después, sincrónico/diacrónico. La composición se construye a lo largo de un orden cronológico, podría afirmarse que todos los diseńos evocan sucesos, ${ }^{53}$ inmersos en

52. Di Peso describe un sistema durante el Periodo Medio en el cual estarían involucradas torres y cimas de cerros, algunos asociados a cerros de trincheras, con el fin de comunicarse de un punto a otro. Ubicada principalmente a lo largo del perímetro oeste, es posible que esta red convergiera en el cerro Moctezuma (Di Peso, Casas Grandes, vol. 2, 364 ).

53. "Designs refered to event not object or idea" (Ruth Bunzel, The Pueblo Potter. A Study of Creative Imagination in Primitive Art [Nueva York: Columbia University Press, 1969], 69). Las informantes zuñi dejan claro que la asociación del nombre de un diseño con el objeto real 
una especie de eternidad, pues no presentan ni punto de inicio ni final. Del mismo modo, los supuestos diseños figurativos parecen suspendidos entre dos realidades, sin posibilidad de discernir si corresponden al mundo animado o al puramente geométrico. La supremacía de representar un aspecto temporal del mundo, más que espacial, dirige a los probables dominios del mito, y por consiguiente, al ritual.

Para Cassirer el verdadero mito nace cuando el hombre atribuye conceptos temporales (nacimiento, devenir, vida) a la figura de los dioses. La primacía de la acción es tal, que es ella, investida en las formas del culto y el ritual, el origen y fundamento del mito. ${ }^{54}$ Mirar el espacio arquitectónico mediante el análisis pictórico, y viceversa, permitió comprender que es la actividad, y por ende el ritual, la que se encuentra inmersa en ambos soportes artísticos. Pero esta ritualidad no debe comprenderse en absoluto ajena al modo normal de vida, pues "la fuerza del sentimiento religioso se manifiesta precisamente en que abarca la totalidad indivisa del ser y del actuar, sin excluir ninguna esfera de la existencia físico-natural, penetrando hasta sus elementos fundamentales y originarios".55 De este modo tanto la pintura como la arquitectura de Casas Grandes, al igual que el ritual, actúan como medio, ${ }^{56}$ su plástica no es representación objetiva de la realidad, sino el culto mismo, el reflejo direc-

es efímero, no significa nada; una alfarera nunca puede explicar la forma, sólo la composición. Curiosamente no hay semejanzas evidentes entre los elementos pictóricos de esta cerámica y la de Casas Grandes, pero las similitudes de los procesos compositivos son sorprendentes, entre los cuales encontramos la inexistencia de simetría bilateral, la composición sometida a la diagonal, variaciones infinitas con el uso de una cantidad ínfima de elementos, la construcción por medio de líneas más que por superficies, búsqueda de equilibrio entre espacio vacío y lleno, y repetición por medio de un carácter rítmico (Bunzel, The Pueblo Potter, 20-7I).

54. Ernst Cassirer, Filosofía de las formas simbólicas II: El pensamiento mítico, trad. Armando Morones (México: Fondo de Cultura Económica, 2013), I4I y 272.

55. Cassirer, Filosofía de las formas simbólicas II, 281.

56. Como medio me refiero al mediador entre el hombre y el mundo circundante del que habla Warburg, aquel que con grandes esfuerzos "hace del espacio una zona de contemplación", Aby Warburg, El ritual de la serpiente, trad. Joaquín Etoreno Homaeche (México: Sexto Piso, 2004), 66.

N.B. El presente ensayo surgió a partir de mi tesis de maestría en Historia del Arte en la Universidad Nacional Autónoma de México. Agradezco el apoyo de John Ware, Eric Kaldahl y Mark Cattanach, de la Amerind Foundation, y de Luis Tena, del Museo de las Culturas del Norte, fundamental para la realización de dicha investigación. Agradezco especialmente a Eduardo Gamboa, director de la Zona Arqueológica de Paquimé, por sus oportunas observaciones sobre el sitio arqueológico. 
to de la conciencia de un pueblo en un determinado momento de su historia; cada una con sus recursos y materiales propios del ámbito en el que operan.

Lamentablemente el conocimiento de sus rituales se limita a los despojos, como los muy citados entierros de aves decapitadas, que en nada traslucen la integridad del rito que seguirá siendo desconocido a nuestros ojos, pero cuyo fondo reside en las manifestaciones que sí se conserva. A partir de sus elementos plásticos el arte de Casas Grandes habla sobre la inexistencia de conceptos de inicio y final en el universo religioso de sus habitantes. El mundo no es comprendido como una totalidad absoluta, sino con relación al movimiento del hombre. Rehúye de la unidad (y por tanto de la dicotomía) a favor de la multiplicidad, pues evita sujetarse a un espacio y tiempo absolutos. Todos sus elementos tienen la capacidad de generar nuevas formas, nuevos espacios. Punto, línea y superficie no existen, salvo como transición entre una forma y otra. ¿De qué rituales habla esta inherente mutabilidad? ¿Recuerdos de un pasado nómada, o persistencias de vida nómada en el presente? ¿ 


\section{Anexo documental}

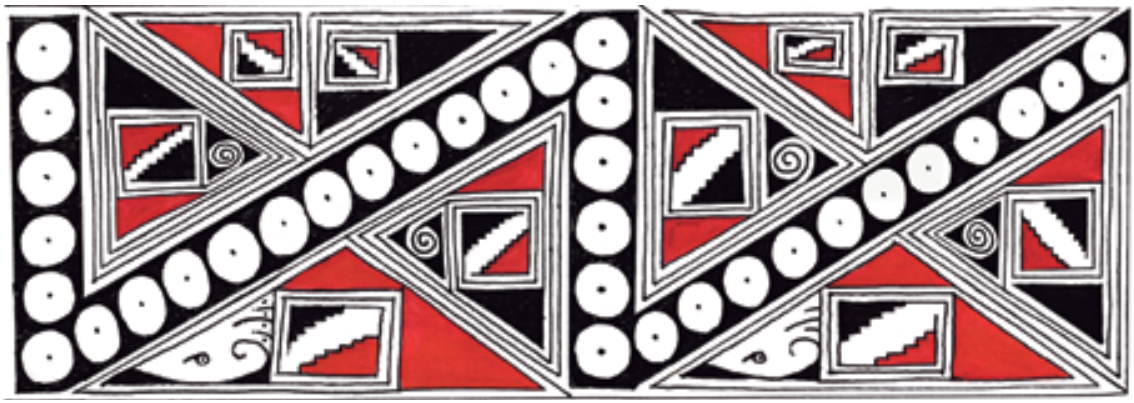

I6. Casas Grandes, diseño de una urna funeraria tipo Ramos polícroma, I300-I450 d. C.

Contenía los huesos largos, sin cráneo, de un hombre mayor. Actualmente en el Museo de las Culturas del Norte. Dibujo: Georgina Parada.

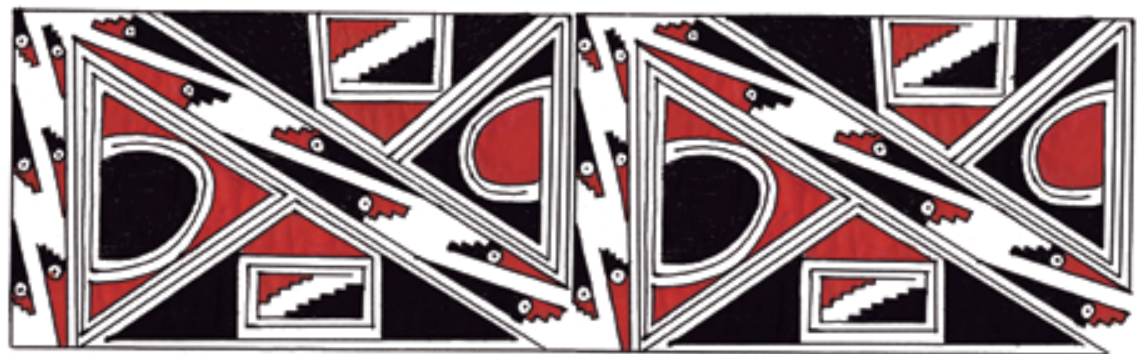

17. Casas Grandes, diseño de una olla tipo Ramos polícroma, I300-I450 d. C. Se encontró como ofrenda funeraria al lado del cuerpo de un niño. Contenía restos de alimento. Actualmente en el Museo de las Culturas del Norte. Dibujo: Georgina Parada.

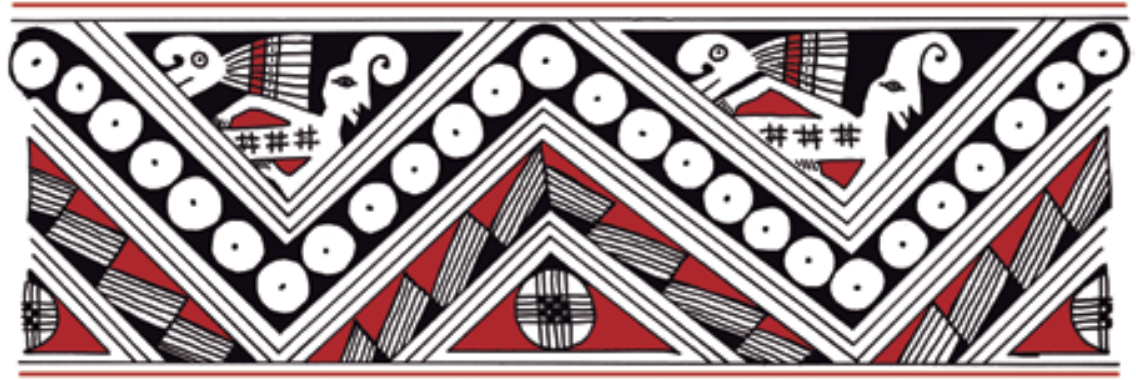

I8. Casas Grandes, diseño de una olla tipo Ramos polícroma, I300-I450 d. C. Actualmente en el Museo de las Culturas del Norte. Dibujo: Alice Wesche, tomado de Di Peso, Rinaldo y Fenner, Casas Grandes (vid. supra n. I), vol. 6, 272 [el color rojo es de la autora]. 


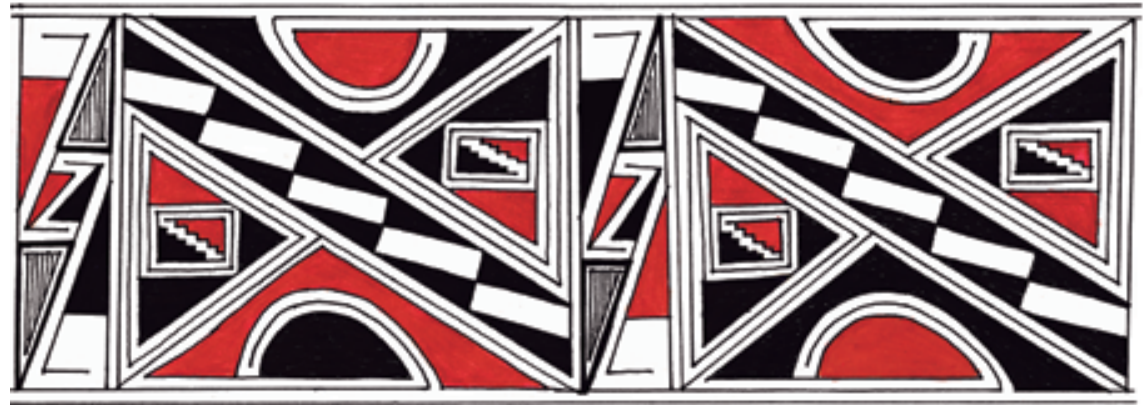

I9. Casas Grandes, diseño de una urna funeraria tipo Ramos polícroma, I300-I450 d. C., Contenía los huesos largos, sin cráneo, de un hombre. Actualmente en el Museo Nacional de Antropología. Dibujo: Georgina Parada.

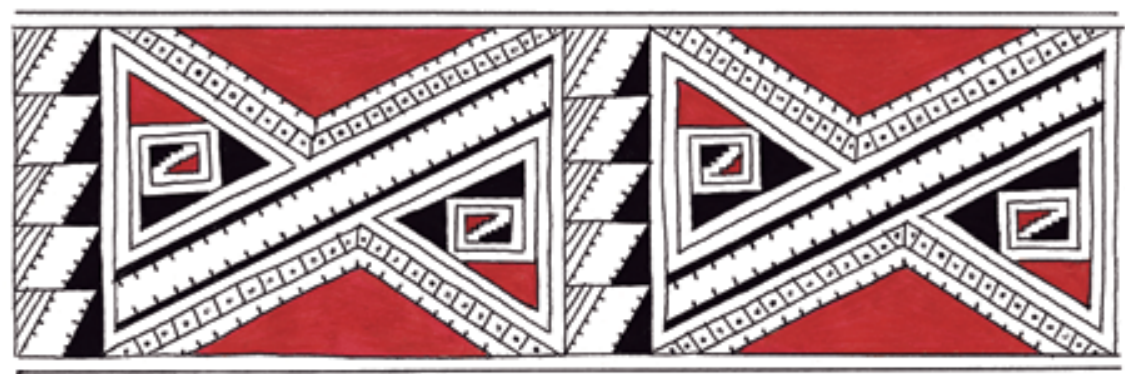

20. Casas Grandes, diseño de una olla tipo Ramos polícroma, I300-I450 d. C. Se encontró como ofrenda funeraria sobre el cuerpo de un hombre. Actualmente en el Museo de las Culturas del Norte. Dibujo: Georgina Parada.

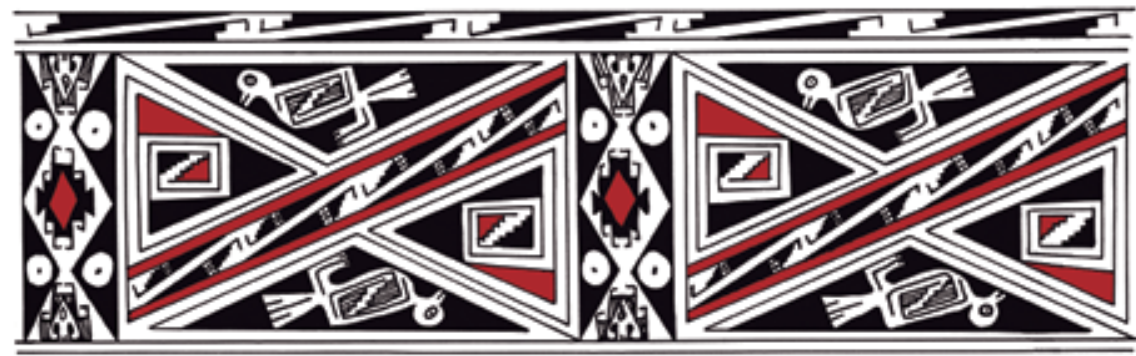

2I. Casas Grandes, diseño de una olla tipo Ramos polícroma, I30O-I45O d. C. Actualmente en el Museo de las Culturas del Norte. Dibujo: Alice Wesche, tomado de Di Peso, Rinaldo, y Fenner, Casas Grandes (vid. supra n. I), vol. 6, 267 [el color rojo es de la autora]. 
DOI: http://dx.doi.org/10.22201/iie.18703062e.2016.109.2580

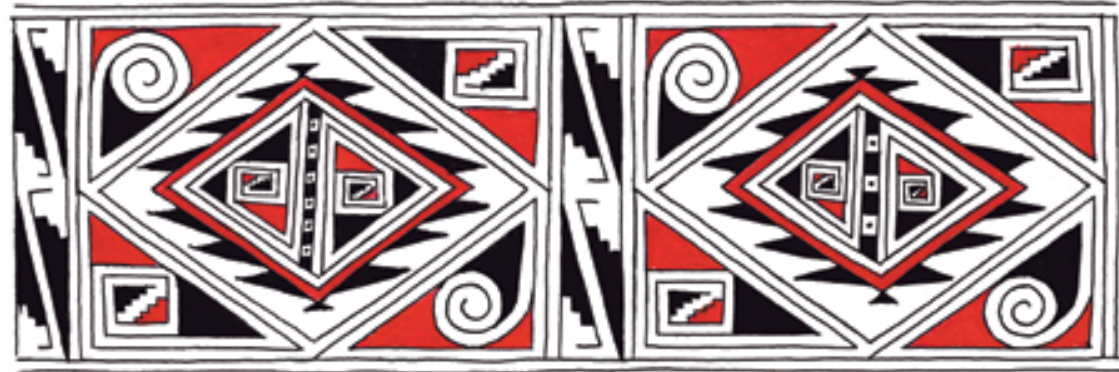

22. Casas Grandes, diseño de una olla tipo Ramos polícroma, I300-I450 d.C. Actualmente en el Museo de las Culturas del Norte. Dibujo: Georgina Parada.

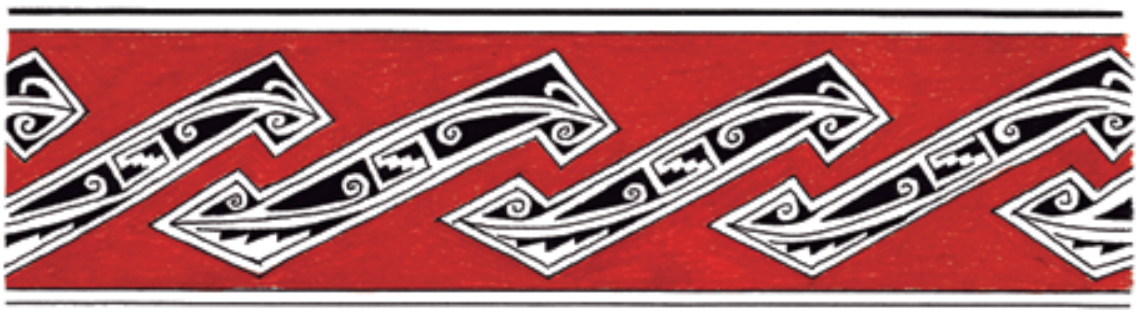

23. Casas Grandes, diseño de una olla tipo Escondida polícroma, I300-I450 d.C. Se encontró como ofrenda funeraria al lado del cuerpo de un hombre. Actualmente en el Museo de las Culturas del Norte. Dibujo: Georgina Parada.

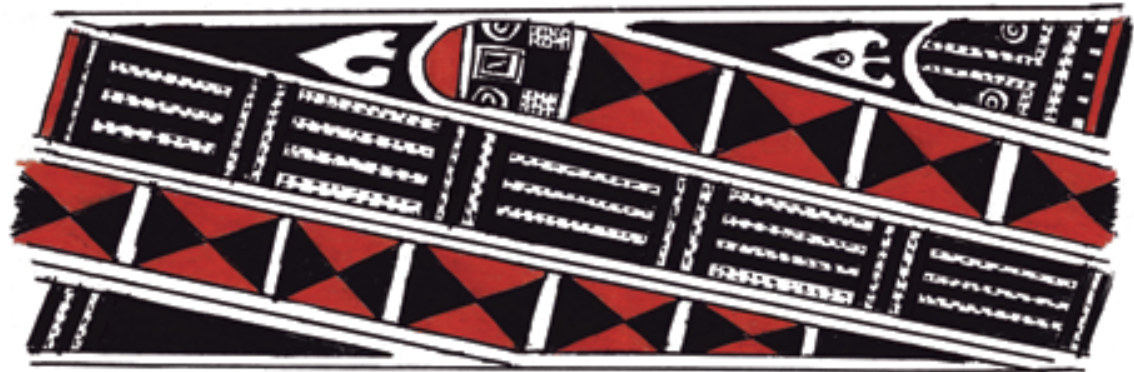

24. Casas Grandes, diseño de una olla tipo Ramos polícroma, I300-I450 d.C. Actualmente en el Museo de las Culturas del Norte. Dibujo: Georgina Parada. 


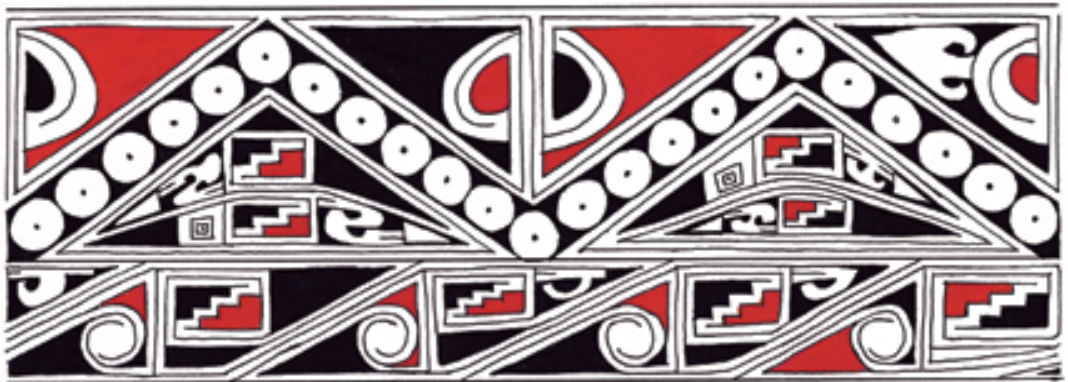

25. Casas Grandes, diseño de una urna funeraria tipo Ramos polícroma I300-I450 d.C. Contenía los huesos largos, sin cráneo, de una mujer. Actualmente en el Museo de las Culturas del Norte. Dibujo: Georgina Parada.

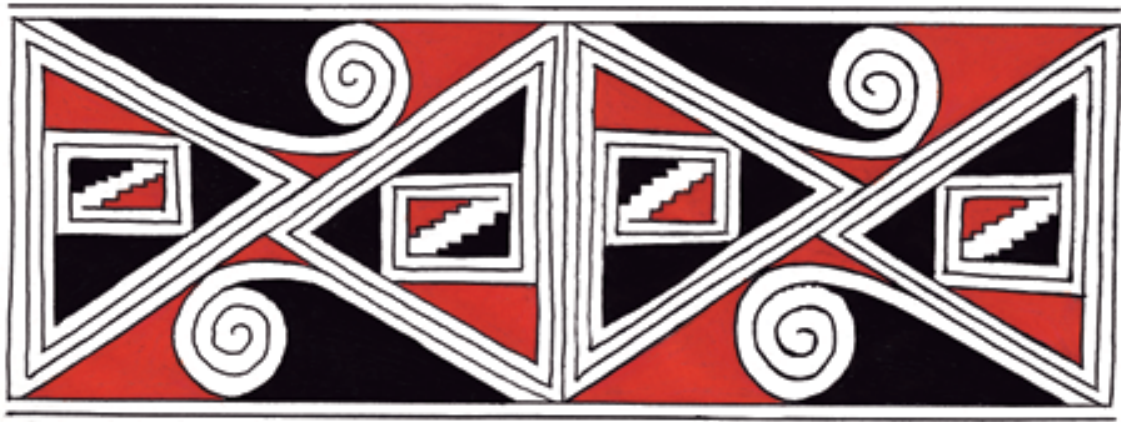

26. Casas Grandes, diseño de una olla tipo Ramos polícroma, I300-I450 d.C. Se encontró como ofrenda funeraria al lado del cuerpo de un hombre. Actualmente en el Museo de las Culturas del Norte. Dibujo: Georgina Parada.

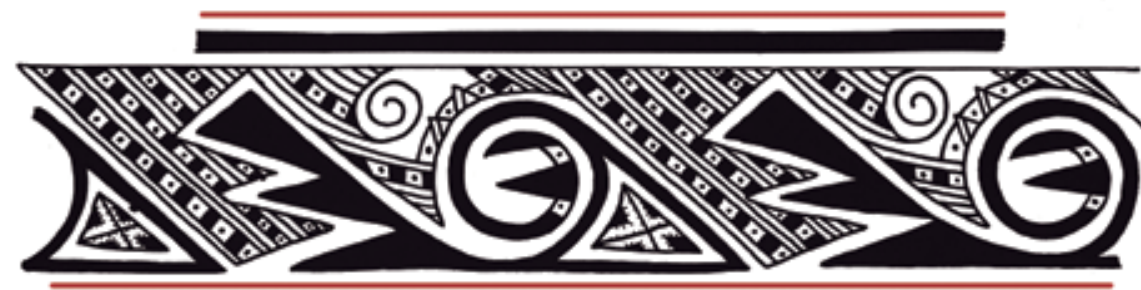

27. Casas Grandes, diseño de una olla tipo Escondida polícroma, I300-I450 d.C. Se encontró como ofrenda funeraria al lado del cuerpo de una mujer. Actualmente en el Museo Nacional de Antropología. Dibujo: Alice Wesche, tomado de Di Peso, Rinaldo y Fenner, Casas Grandes (vid. supra n. I), vol. 6, 235 [el color rojo es de la autora]. 
DOI: http://dx.doi.org/10.22201/iie.18703062e.2016.109.2580

$2 \mathrm{I} 2$

GEORGINA PARADA CARRILLO
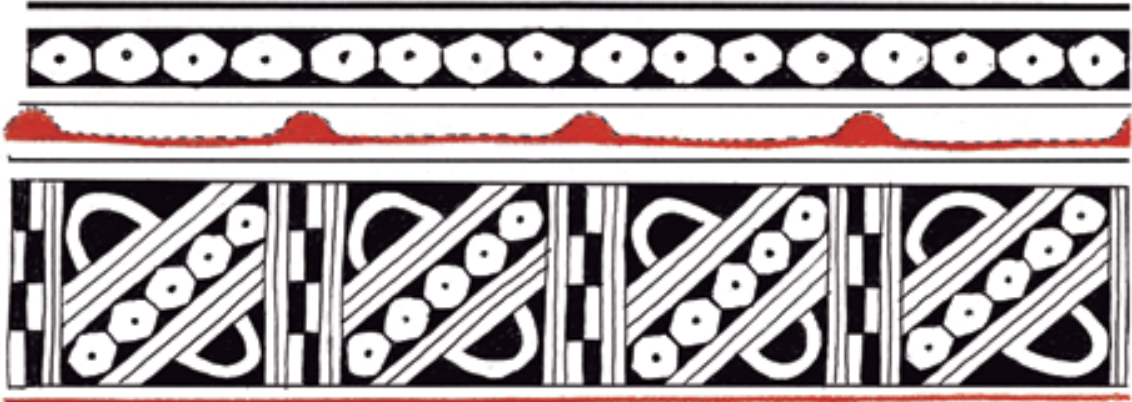

28. Casas Grandes, diseño de una olla tipo Villa Ahumada polícroma, I300-I450 d.C.

Actualmente en el Museo Nacional de Antropología. Dibujo: Georgina Parada.

29. Casas Grandes, diseño de un cajete tipo Ramos polícromo, I300-I450 d.C. Actualmente en el Museo Nacional de Antropología. Dibujo: Georgina Parada.
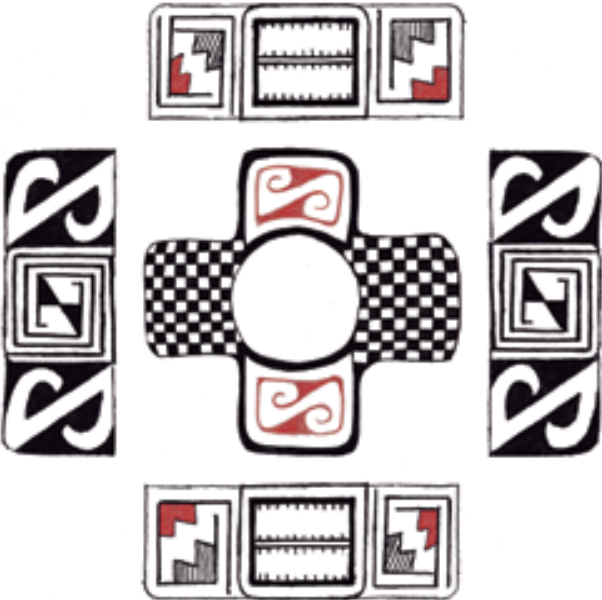


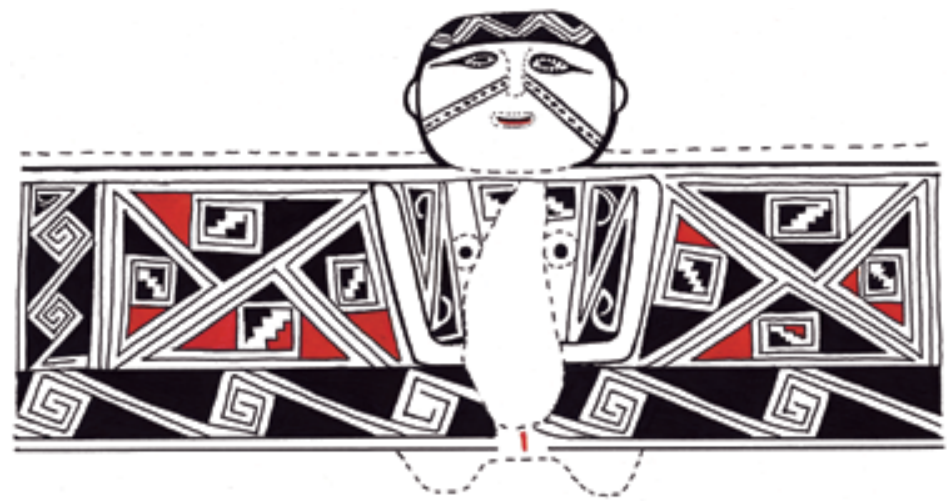

30. Casas Grandes, diseño de una vasija-efigie tipo Ramos polícroma, I300-I450 d.C. Actualmente en el Museo de las Culturas del Norte. Dibujo: Georgina Parada.

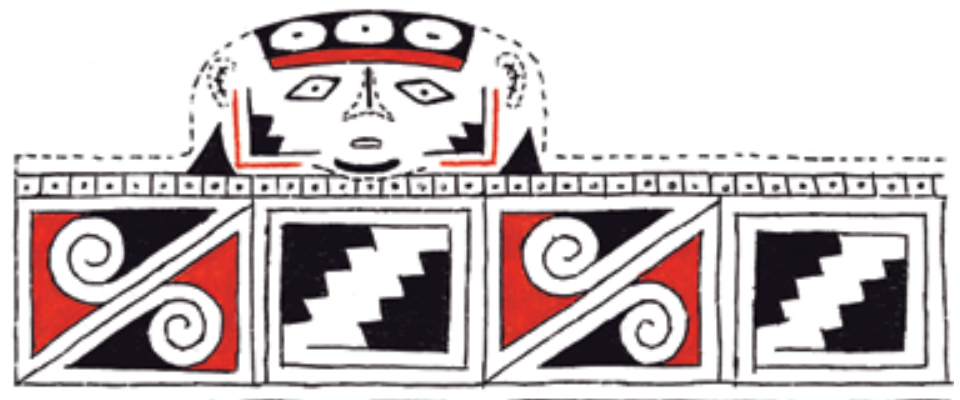

31. Casas Grandes, diseño de una vasija-efigie tipo Ramos polícroma, ızooI45o d.C., se le contró como ofrenda al lado del cuerpo de un niño y los huesos de un infante. Actualmente en el Museo Nacional de Antropología. Dibujo: Georgina Parada.

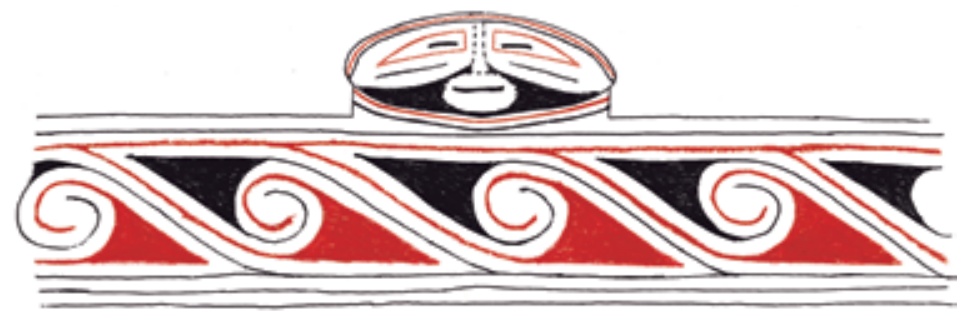

32. Casas Grandes, diseño de una vasija-efigie tipo Villa Ahumada polícroma, I300-I45o d.C. Se encontró como ofrenda funeraria al lado del cuerpo de un nińo. Actualmente en el Museo de las Culturas del Norte. Dibujo: Georgina Parada. 


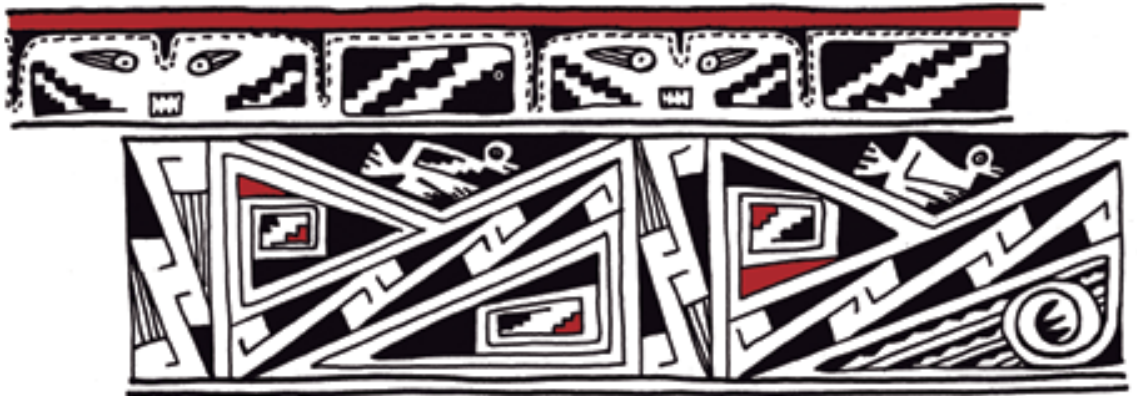

33. Casas Grandes, diseño de una vasija-efigie tipo Ramos polícroma, I300-I450 d.C. Se encontró como ofrenda funeraria al lado de los cuerpos de dos hombres. Actualmente se en el Museo de las Culturas del Norte. Dibujo: Alice Wesche, tomado de Di Peso, Rinaldo y Fenner, Casas Grandes (vid. supra n. I), vol. 6, 268 [el rojo es de la autora].

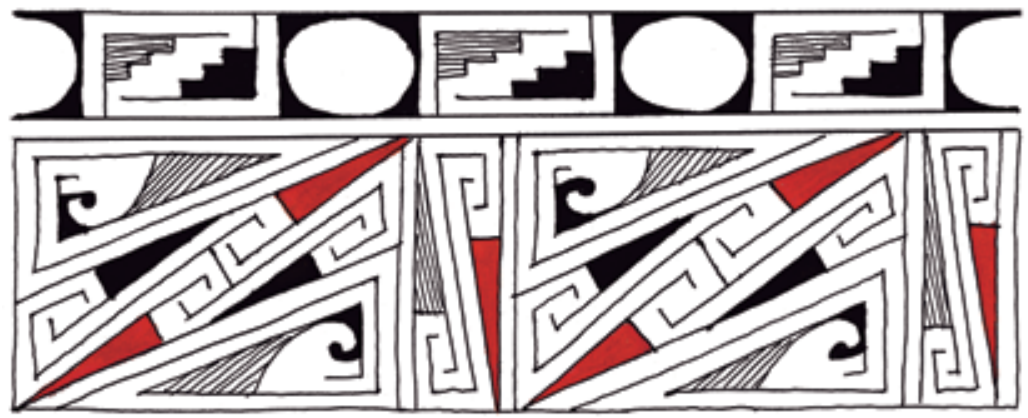

34. Casas Grandes, diseño de una olla tipo Ramos polícroma, I300-I450 d.C. Se encontró como ofrenda funeraria al lado del cuerpo de una mujer mayor. Actualmente en el Museo Nacional de Antropología. Dibujo: Georgina Parada.

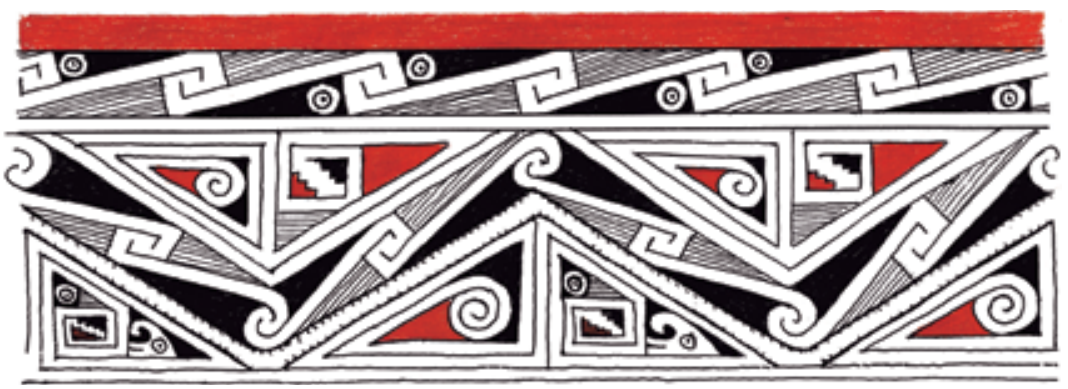

35. Casas Grandes, diseño de una olla tipo Ramos polícroma, I300-I450 d.C. Se le encontró como ofrenda funeraria a los pies de un adolescente. Actualmente en el Museo de las Culturas del Norte. Dibujo: Georgina Parada. 